\title{
LA PROTECCIÓN DE LOS DERECHOS SOCIALES COMO DERECHOS FUNDAMENTALES DE EFICACIA INMEDIATA Y JUSTICIABLES EN JURISDICCIÓN CONSTITUCIONAL: LA SENTENCIA DEL TRIBUNAL CONSTITUCIONAL ROL 1710-2010-INC., DEL 6 DE AGOSTO DE 2010, SOBRE LA CONSTITUCIONALIDAD DEL ARTÍCULO 38 TER DE LA LEY DE ISAPRES
}

Humberto Nogueira Alcalá ${ }^{1}$

\section{INTRODUCCIÓN}

En Chile, las personas tienen el derecho de optar por recibir las prestaciones de salud en instituciones de salud pública o en instituciones de salud privadas (Instituciones de Salud Previsional, ISAPRES). Los deberes impuestos al Estado en virtud de la Constitución, como asimismo a las ISAPRES, se encuentran reguladas en el D.F.L. No 1, de 2005, que fijó el texto refundido, coordinado y sistematizado del Decreto Ley No 2.763, de 1979 y de las Leyes $\mathrm{No}^{\text {s. }} 18.933$ y 18.469. En ambos casos, tanto la institucionalidad pública como en el de las ISAPRES, otorgan las prestaciones de salud con cargo a cotizaciones obligatorias legalmente establecidas que reciben las instituciones de salud de los beneficiarios de las prestaciones. En el caso de las ISAPRES el plan de salud es contratado por los beneficiarios y éste tiene un precio fijado por las Isapres, atendiendo el tipo de prestaciones y los montos de los gastos cubiertos por ellas. Entre las condiciones estipuladas en la ley está la posibilidad de las Isapres de revisar los precios de los planes de salud que ofrecen. Para tal efecto deben aplicar a los precios base "el o los factores que correspondan a cada beneficiario, de acuerdo a la respectiva tabla de factores", de acuerdo al artículo 199 inc. $1^{\circ}$ de la ley. La estructura de la tabla de

\footnotetext{
${ }^{1}$ El autor es Director del Centro de Estudios Constitucionales de Chile, Universidad de Talca, Campus Santiago. Director del Magíster en Derecho Constitucional, Universidad de Talca. Doctor en Derecho por la Universidad Católica de Lovaina la Nueva. Presidente de la Asociación Chilena de Derecho Constitucional. Vicepresidente del Instituto Iberoamericano de Derecho Procesal Constitucional y miembro de la Academia Internacional de Derecho Comparado de La Haya, Holanda. nogueira@utalca.cl
} 
factores es fijada por la Superintendencia de Salud mediante acto administrativo, de acuerdo a lo que establece la misma ley.

El tema objeto de análisis y determinación de su eventual expulsión del ordenamiento jurídico es un conjunto de disposiciones que integran el actual artículo 199 de la Ley de ISAPRES en su texto refundido, coordinado y sistematizado, aprobado por el Decreto con Fuerza de Ley No 1, de 2005, del Ministerio de Salud, que corresponde al antiguo artículo 38 ter de la Ley No 18.933.

El problema es adecuadamente planteado en los respectivos considerandos del fallo del Tribunal Constitucional, los cuales determinan lo siguiente:

"QUINCUAGÉSIMO: Que el artículo 38 ter de la Ley No 18.933, que corresponde al artículo 199 del D.F.L. No 1, de 2005, del Ministerio de Salud, que fijó el texto refundido, coordinado y sistematizado del D.L. No 2.763, de 1979, y de las leyes $N{ }^{o} .18 .933$ y 18.469, dispone lo siguiente:

"Artículo 38 ter.- Para determinar el precio que el afiliado deberá pagar a la Institución de Salud Previsional por el plan de salud, la Institución deberá aplicar a los precios base que resulten de lo dispuesto en el articulo precedente, el o los factores que correspondan a cada beneficiario, de acuerdo a la respectiva tabla de factores.

La Superintendencia fijará, mediante instrucciones de general aplicación, la estructura de las tablas de factores, estableciendo los tipos de beneficiarios, según sexo y condición de cotizante o carga, y los rangos de edad que se deban utilizar.

Cada rango de edad que fije la Superintendencia en las instrucciones señaladas en el inciso precedente se sujetará a las siguientes reglas:

1.- El primer tramo comenzará desde el nacimiento y se extenderá hasta menos de dos años de edad;

2.- Los siguientes tramos, desde los dos años de edad y hasta menos de ochenta años de edad, comprenderán un minimo de tres años y un máximo de cinco años;

3.- La Superintendencia fijará, desde los ochenta años de edad, el o los tramos que correspondan;

4.- La Superintendencia deberá fijar, cada diez años, la relación máxima entre el factor más bajo y el más alto de cada tabla, diferenciada por sexo;

5.- En cada tramo, el factor que corresponda a una carga no podrá ser superior al factor que corresponda a un cotizante del mismo sexo.

En el marco de lo señalado en el inciso precedente, las Instituciones de Salud Previsional serán libres para determinar los factores de cada tabla que empleen. En todo caso, la tabla de un determinado plan de salud no podrá variar para los beneficiarios mientras se encuentren adscritos al mismo, ni podrá alterarse para quienes se incorporen a él, a menos que la modificación consista en disminuir de forma permanente los factores, total o parcialmente, lo que requerirá autorización previa de la Superintendencia; dicha disminución se hará aplicable a todos los planes de salud que utilicen esa tabla. 
Cada plan de salud sólo podrá tener incorporada una tabla de factores. Las Instituciones de Salud Previsional no podrán establecer más de dos tablas de factores para la totalidad de los planes de salud que se encuentren en comercialización.

Sin perjuicio de lo dispuesto en el inciso precedente, las Instituciones de Salud Previsional podrán establecer nuevas tablas cada cinco años, contados desde las últimas informadas a la Superintendencia, manteniéndose vigentes las anteriores en los planes de salud que las hayan incorporado.

Las Instituciones de Salud Previsional estarán obligadas a aplicar, desde el mes en que se cumpla la anualidad y de conformidad con la respectiva tabla, el aumento o la reducción de factor que corresponda a un beneficiario en razón de su edad, y a informar al cotizante respectivo mediante carta certificada expedida en la misma oportunidad a que se refiere el inciso tercero del artículo 38";

QUINCUAGÉSIMO PRIMERO: Que, como se observa, el artículo 38 ter transcrito constituye una norma de estructura compleja, destinada a regular una serie de materias sobre la determinación del precio de los planes de salud contratados con las Instituciones de Salud Previsional, no sólo vinculadas estrechamente entre sí, sino también con otras disposiciones de la Ley $N^{\circ}$ 18.933. Tales características determinan que el examen de constitucionalidad de autos debe distinguir entre los diferentes aspectos que el precepto trata y tener en cuenta el efecto que una decisión de inconstitucionalidad tendría en las otras normas de la ley vinculadas con él;

QUINCUAGÉSIMO SEGUNDO: Que el primer inciso de ese artículo está destinado a establecer el procedimiento para determinar el precio del plan de salud que cada af-liado está obligado a pagar a la respectiva Isapre, aun cuando contempla un componente dispuesto en el artículo 38 bis de la misma ley-correspondiente al artículo 198 del texto refundido de la ley-al que se aplican los factores que corresponden a cada beneficiario de acuerdo a la respectiva tabla;

QUINCUAGESIMO TERCERO: Que, dado que el artículo 38 bis al que alude el artículo 38 ter no se encuentra sujeto al examen de constitucionalidad de autos, el pronunciamiento de esta Magistratura no puede recaer sobre el precio base cuya determinación aquél regula, sino sobre los factores resultantes de las respectivas tablas;

QUINCUAGÉSIMO CUARTO: Que la tabla de factores aludida es aquélla definida en la letra $n$ ) del artículo $2^{\circ}$ de la Ley $N^{\circ} 18.933$, actual artículo 170 en el texto refundido de dicha legislación (D.F.L. No 1, de Salud, de 2005), en los términos siguientes: "Artículo 170.- Para los fines (de la Ley $N^{\circ} 18.933$ ) de este Libro se entenderá: n) La expresión "tabla de factores" por aquella tabla elaborada por la Institución de Salud Previsional cuyos factores muestran la relación de precios del plan de salud para cada grupo de personas, según edad, sexo y condición de cotizante o carga, con respecto a un grupo de referencia definido por la Superintendencia, en instrucciones de general aplicación, el cual asumirá el valor unitario. Esta tabla representa un mecanismo pactado de variación del precio del plan a lo largo del ciclo de vida, el que es conocido y aceptado por el afiliado o 
beneficiario al momento de suscribir el contrato o incorporarse a él, según corresponda, y que no podrá sufrir variaciones en tanto la persona permanezca adscrita a ese plan"; QUINCUAGESIMO QUINTO: Que en el segundo inciso del articulo 38 ter se dispone la obligación, que recae en la Superintendencia de Salud, de fijar, mediante instrucciones de aplicación general, la estructura de las tablas de factores que deberán utilizar las Isapres en los contratos de salud que ofrezcan a sus afiliados. Como se observa, esta norma no hace sino reiterar lo ya establecido en el artículo 170 citado. Al mismo tiempo, la norma impone que la referida estructura considere los tipos de beneficiarios, según sexo y condición de cotizante o de carga, y los rangos de edad que se deban utilizar, conforme, esto último, a las reglas establecidas en su inciso tercero, a las que se hará alusión en seguida;

QUINCUAGÉSIMO SEXTO: Que en el segundo inciso del artículo 38 ter se dispone la obligación que recae en la Superintendencia de Salud, de fijar, mediante instrucciones de aplicación general, la estructura de las tablas de factores que deberán utilizar las Isapres en los contratos de salud que ofrezcan a sus afiliados. Como se observa, esta norma no hace sino reiterar lo ya establecido en el artículo 170 ya citado. Esta norma faculta a la Superintendencia del ramo para ejercer esta potestad. Para determinar el contenido y los criterios conforme a los cuales ella debe ejercerse, hay que atender a lo prescrito en el inciso siguiente, el cual impone que la referida estructura considere los tipos de beneficiarios, según sexo y condición de cotizante o de carga, y los rangos de edad que se deben utilizar conforme a las reglas establecidas en su inciso tercero.

Así, este inciso segundo sólo puede concebirse en relación a los numerales contenidos en el inciso tercero, en el cual se fijan los parámetros que debe considerar la Superintendencia al determinar la estructura de la tabla;

QUINCUAGÉSIMO SÉPTIMO: Que el tercer inciso del artículo 38 ter establece las reglas a las que debe sujetarse la fijación de los rangos de edad en las instrucciones impartidas por la Superintendencia, de las cuales tres se refieren directamente a los tramos de edad y las otras dos, a criterios de relación entre los factores. La observancia de estas reglas es una condición de ejercicio, tanto de la potestad de la Superintendencia para fijar la estructura de las tablas de factores regulada en el inciso segundo, como de la libre determinación de los factores dentro de la tabla por parte de las Isapres, conforme al inciso cuarto;

QUINCUAGÉSIMO OCTAVO: Que las tres primeras reglas relativas a los rangos de edad están destinadas a fijar tramos según se sigue: i) Un tramo desde el nacimiento hasta menos de dos años, ii) Los tramos que van desde los dos años hasta los ochenta años, según límites de un mínimo de tres años y un máximo de cinco años, y iii) El o los tramos "que correspondan" después de los ochenta años, fijados por la Superintendencia. Debe señalarse que el segundo grupo de tramos es, en verdad, un amplio espacio etáreo en el que pueden tener cabida entre 15 y 26 tramos, dependiendo de la cantidad de años máxima o minima establecida en la norma;

QUINCUAGÉSIMO NOVENO: Que en el número 4 del mencionado inciso tercero del artículo 38 ter se establece el primer criterio de relación entre los factores, el cual consiste 
en entregar a la Superintendencia la facultad de fijar, cada diez años, la relación máxima entre el factor más bajo y el más alto de la tabla, diferenciada por sexo;

SEXAGESIMO: Que, sin embargo, fue el propio legislador el que fijó dicha relación entre factores para el primer período de diez años, por la Ley $N^{\circ} 20.015$, de 17 de mayo de 2005 -la misma legislación que incorporó el artículo 38 ter bajo examen-. En efecto, su artículo segundo transitorio dispone: "La relación máxima a que alude el numeral 4 del inciso tercero del artículo 38 ter que se agrega a la Ley $N^{\circ} 18.933$ será, para el primer decenio contado desde la vigencia de la presente ley, de hasta 9 veces, en el caso de las mujeres, y de hasta 14 veces, en el caso de los hombres".

SEXAGÉSIMO PRIMERO: Que la Superintendencia de Salud materializó la facultad que le entrega el precepto legal bajo examen y que especificó el artículo segundo transitorio citado, a través de la Circular No 6, de 2 de junio de 2005, denominada "IMPARTE INSTRUCCIONES SOBRE LA ESTRUCTURA DE LAS TABLAS DE FACTORES DE LOS PLANES DE SALUD COMPLEMENTARIOS”. En dicho instrumento el referido organismo público estableció la estructura de la aludida tabla de factores, fijando los factores más altos y más bajos de acuerdo al tenor legal señalando: "La relación máxima entre el factor más bajo y el más alto de cada tabla será de hasta 9 veces, en el caso de las mujeres, y de hasta 14 veces, en el caso de los hombres, para el periodo comprendido entre el 1 de julio de 2005 y el 1 de julio de 2015";

SEXAGÉSIMO SEGUNDO: Que la correspondencia entre estas dos normas originadas en la misma ley $-N^{\circ}$ 20.015-, el número 4 del inciso tercero del artículo 38 ter y el articulo segundo transitorio de la Ley $N^{\circ} 20.015$, establece entre ellas un lazo juridicamente indisoluble, de tal modo que ninguna de ambas cobra vigencia y eficacia sin el complemento de la otra. En efecto, el mandato que la ley le asigna a la Superintendencia del ramo para fijar "cada diez años la relación máxima entre el factor más alto y el más bajo, diferenciada por sexo" es inocuo sin la correspondiente determinación cuantitativa de uno y de otro extremo, asi como respecto al sexo del beneficiario. Por su parte, ni la ley ni la Superintendencia podrian haber fijado cifras respecto de los mencionados factores sin remitirse al mencionado articulo 38 ter y a la cobertura que proporciona;

SEXAGÉSIMO TERCERO: Que a resultas de lo expresado y como se detallará, la indisolubilidad señalada presenta a las dos normas involucradas como un todo para los efectos del examen de constitucionalidad de autos;

SEXAGÉSIMO CUARTO: Que el segundo criterio de relación establecido en este inciso tercero del articulo bajo examen, se refiere a la correspondencia que debe existir entre los beneficiarios de un mismo plan, al señalar que "en cada tramo, el factor que corresponda a una carga no podrá ser superior al factor que corresponda a un cotizante del mismo sexo";

SEXAGÉSIMO QUINTO: Que los cuatro incisos siguientes del artículo 38 ter están destinados a regular la proporcionalidad que deben cumplir los distintos tramos al interior de las tablas de factores. Primero se establece la libertad de las Isapres para determinar los factores de cada tabla, conforme a lo dispuesto en el inciso tercero ya comentado, de 
modo que las reglas que se analizaron también determinan el ejercicio de este derecho. La ley dispone expresamente la no variabilidad de la tabla de un determinado plan para los beneficiarios mientras se encuentren adscritos a él, así como también para quienes se incorporen al mismo, a excepción que la modificación signifique una disminución de los factores, autorizada por la Superintendencia y aplicable a todos los planes que la utilicen. Asi, no se reconoce discrecionalidad amplia a las Isapres para determinar los factores de cada tabla, sino sólo en la medida que lo hagan utilizando la tabla de factores estructurada de conformidad a los numerales del inciso tercero. Luego, los incisos siguientes señalan exigencias sobre el número de tablas, una por cada plan de salud y no más de dos para la totalidad de planes que se comercializan por la respectiva Isapre. Asimismo, conforme a la regulación legal en comento, las Isapres podrán establecer nuevas tablas cada cinco años;

SEXAGÉSIMO SEXTO: Que el último inciso del artículo 38 ter se refiere a la obligación que periódicamente les cabe a las Isapres, en el sentido de ajustar el factor que corresponda en la respectiva tabla en razón de la edad, aumentándolo o disminuyéndolo, y de comunicar tales variaciones al cotizante;".

\section{LA ACCIÓN DE INCONSTITUCIONALIDAD DEL ARTÍCULO $93 \mathrm{~N}^{\circ} 7$ Y SUS CARACTERÍSTICAS BÁSICAS}

La acción de inconstitucionalidad prevista en el artículo $93 \mathrm{~N}^{\circ} 7$ tiene como legitimación activa a cualquier ciudadano (acción pública o popular) o al Tribunal Constitucional de oficio.

En el caso analizado, el Tribunal Constitucional debe, en virtud de su decisión de oficio, conforme al artículo 93 No 7 de la Constitución, someter las disposiciones constitucionalmente cuestionadas de la Ley de ISAPRES a un control de inconstitucionalidad, en procedimiento abstracto, aun cuando este control jurisdiccional en nuestro ordenamiento constitucional está sujeto a modalidades específicas que no se encuentran comúnmente en el derecho comparado, restringiéndolo sustantivamente.

En efecto, dicho control únicamente es posible de ser activado por los legitimados activos (cualquier ciudadano o el Tribunal Constitucional de oficio) si, previamente, el Tribunal ya se ha pronunciado, en a lo menos una sentencia, respecto de una acción de inaplicabilidad acogiéndola, en control concreto, sobre el mismo enunciado legal, decisión jurisdiccional que sólo implica determinar que, en dicho caso concreto, la aplicación del enunciado legal genera una situación de inconstitucionalidad. A ello debe agregarse una segunda restricción al ejercicio de la acción de inconstitucionalidad, ella consiste en que sólo puede referirse a los vicios de inconstitucionalidad ya detectados y declarados en las sentencias previas 
de inaplicabilidad en control concreto, por lo cual el Tribunal Constitucional no puede pronunciarse sobre otros vicios de inconstitucionalidad que puedan tener los preceptos legales objeto de análisis en control abstracto de inconstitucionalidad.

En el presente caso, el Tribunal Constitucional ya había dictado cuatro sentencias de inaplicabilidad por inconstitucionalidad conforme al artículo 93 No 6 de la Constitución, sobre la materia. Una tercera restricción que enfrenta la acción de inconstitucionalidad es que para ser acogida por el Tribunal Constitucional, la sentencia debe pronunciarse por los cuatro quintos de los ministros del Tribunal Constitucional.

En tal perspectiva, la propia sentencia analizada dispone que:

"CENTÉSIMO SEPTUAGÉSIMO SEGUNDO: Que, por las argumentaciones desarrolladas en esta sentencia, queda demostrado que se declarará la inconstitucionalidad de los preceptos en cuestión basándose en los mismos vicios detectados en los casos ya resueltos en sede de inaplicabilidad;

"CENTÉSIMO SEPTUAGÉSIMO TERCERO: Que, dilucidándose la cuestión de autos, es necesario distinguir, como ya se hizo en esta sentencia en las letras $C y E$ del apartado I, la facultad que el artículo 93, inciso primero, $N^{\circ} 6^{\circ}$, de la Constitución otorga a este Tribunal de aquella establecida en el $N^{\circ} 7^{\circ}$ del mismo artículo y que se ejerce en este proceso. Se trata de situaciones de distinto alcance, supuestos y efectos. Mientras en el primer caso se está frente a una contradicción concreta, en atención al caso especifico, entre una determinada aplicación de un precepto legal y la Constitución, en la segunda se afronta una situación de contradicción abstracta, absoluta y palmaria entre un precepto legal-sin considerar sus aplicaciones concretas-y la Constitución;".

A su vez, el Tribunal Constitucional en este fallo dedica varios considerandos a precisar que, si bien debe siempre referirse a los vicios ya predeterminados en las sentencias de inaplicabilidad previas, ello no le impide abundar en nuevos y complementarios argumentos jurídicos sobre tales vicios, que se adicionan o complementan los ya expresados en las sentencias de inaplicabilidad, criterio que compartimos plenamente:

"CENTÉSIMO SEPTUAGÉSIMO CUARTO: Que la diferencia descrita exige una distinta fundamentación de una y otra decisión. En efecto, en primer lugar, la Constitución exige congruencia entre las decisiones pasadas y la declaración de inconstitucionalidad, pero no una igualdad de argumentaciones. Cada uno de los exámenes de constitucionalidad de la ley va creando un verdadero sistema donde los controles pasados "despejan" a los futuros. Asi, el control preventivo de la ley (artículos 37 y 45 bis de la Ley $N^{o} 17.997$ ) se vincula con la acción de inaplicabilidad (artículos $47 \mathrm{~B}$ y $47 \mathrm{~F}, N^{\circ} 2$, de la Ley $N^{\circ}$ 17.997) yésta a la declaración de inconstitucionalidad (artículos $47 \mathrm{R}$ y $47 \mathrm{~V}$ de la Ley $N^{\circ}$ 17.997); 
CENTÉSIMO SEPTUAGÉSIMO QUINTO: Que, a través de tal mecanismo, la Constitución y la Ley Orgánica Constitucional aludida exigen a este Tribunal ser coherente en la identificación de los vicios en cada una de las etapas sucesivas del control de constitucionalidad de la ley, por cuanto éstos pueden presentarse en distintos casos y demostrarse de manera diferente. En todo caso, en sede de inconstitucionalidad el Tribunal no puede ampliar su campo de acción a infracciones constitucionales sobre las que no se ha pronunciado antes. En otras palabras, lo que le está impedido hacer a esta Magistratura es ampliar los vicios que justifican su fallo, pero no asi el abundar en las razones que le sirven de apoyo;

CENTÉSIMO SEPTUAGÉSIMO SEXTO: Que, por tanto, aunque se trate del mismo vicio, es posible fundamentar su existencia de un modo distinto a lo declarado en las inaplicabilidades previas. Si el Tribunal estuviera vinculado por las consideraciones que tuvo en el pasado, la facultad del artículo 93, inciso primero, $N^{\circ} 7^{\circ}$, constitucional perdería sentido. Ella sería prácticamente automática e indistinguible de las inaplicabilidades;

CENTÉSIMO SEPTUAGÉSIMO SÉPTIMO: Que, a su vez, el vicio cuya existencia se exige consiste en una contradicción entre el precepto legal que fue declarado inaplicable y la Constitución. Por lo tanto, hay que buscar una identidad entre los preceptos constitucionales que fueron considerados como infringidos en sede de inaplicabilidad y la declaración de inconstitucionalidad; no en la argumentación empleada en aquélla. Ello se demuestra en la forma en que está redactado el artículo $47 \mathrm{~V}$ de la Ley Orgánica Constitucional del Tribunal, que señala: "la declaración de inconstitucionalidad de las normas legales cuestionadas deberá fundarse unicamente en la infracción del o los preceptos constitucionales que fueron considerados transgredidos por la sentencia previa de inaplicabilidad que le sirve de sustento;".

\section{LAS NORMAS CONSTITUCIONALES QUE OPERAN COMO PARÁMETRO DE CONTROL Y SU INTERPRETACIÓN}

Respecto de las normas constitucionales que son parámetro de control de constitucionalidad respecto de las normas legales impugnadas, ellas son la dignidad de la persona humana (artículo $1^{\circ}$ de la Constitución), la igualdad ante la ley (artículo 19 No 2); el derecho fundamental a la protección de la salud (artículo 19 No 9) y el derecho a la seguridad social (artículo 19 No 18).

El Tribunal Constitucional realiza una interpretación unitaria, sistemática y finalista del texto constitucional, postulados que hoy son pacíficos en el ámbito de la jurisdicción constitucional comparada y en materia de interpretación de los derechos fundamentales.

Las sentencias del Tribunal Constitucional, roles $\mathrm{No}^{\circ}$. 1273 y 1710, en sus considerandos $47^{\circ}$ y $88^{\circ}$, respectivamente, ya habían precisado que los derechos 
"no pueden ser considerados de manera aislada o independiente unos de otros. Al contrario, ellos se manifiestan de manera integrada, constituyendo un entramado de normas y principios cuyo alcance no puede apreciarse correctamente sin considerar una visión de conjunto que los incluya a todos ellos y que, también, incorpore su relación con otras disposiciones y valores constitucionales".

\section{LA INDIVISIBILIDAD E INTERDEPENDENCIA Y COMPLEMENTARIEDAD DE LOS DERECHOS INDIVIDUALES Y LOS DERECHOS SOCIALES}

El Tribunal Constitucional en diversos fallos, las sentencias roles $\mathrm{No}^{\circ} .976$, 1218,1287 , en sus respectivos considerandos $32^{\circ}$, ya había afirmado la interdependencia de los derechos sociales y derechos individuales, del derecho a la salud con el derecho a la vida y a la integridad tanto física como psíquica, todos los cuales deben ser tutelados y promovidos para infundir al ordenamiento jurídico.

La Asamblea General de Naciones Unidas, ya en la Resolución No 32/130 de 16 de diciembre de 1977, determinó que:

“a) Todos los derechos humanos y libertades fundamentales son indivisibles e interdependientes, deberá prestarse la misma atención y urgente consideración a la aplicación, la promoción y protección tanto de los derechos civiles y politicos como de los derechos económicos, sociales y culturales;

“b) 'La plena realización de los derechos civiles y políticos sin el goce de los derechos económicos, sociales y culturales resulta imposible; la consecución de un progreso duradero en la aplicación de los derechos humanos depende de unas buenas y eficaces políticas nacionales e internacionales de desarrollo económico y social', como lo reconoce en la proclamación de Teherán de 1968"2.

A su vez, la Conferencia Mundial de Derechos Humanos de Viena de junio de 1993, en la Declaración y el Programa de Acción de Viena, se determina en su artículo $5^{\circ}$ :

"Todos los derechos humanos son universales, indivisibles e interdependientes y están relacionados entre sí. La comunidad internacional debe tratar los derechos de forma global y de manera justa y equitativa, en pie de igualdad y dándoles a todos un mismo peso. Debe tenerse en cuenta la importancia de las particularidades nacionales y regionales, así como

\footnotetext{
${ }^{2}$ CASAL, Jesús María. "La protección internacional y constitucional de los derechos sociales”. CASAL, Jesús María; Arismendi, Alfredo y Carrillo, Carlos Luis (coordinadores). Tendencias actuales del derecho constitucional. Homenaje a Jesús María Casal Montbrun. Tomo II. ED. Universidad Central de Venezuela-Universidad Católica Andrés Bello, Caracas, Venezuela, 2007, p. 11.
} 
los diversos patrimonios históricos, además los Estados tienen el deber, sean cuales fueren sus sistemas politicos, económicos y culturales, de promover y proteger todos los derechos humanos y las libertades fundamentales"3.

También la Declaración de Quito del 24 de julio de 1998 en su preámbulo:

"[...] los derechos económicos, sociales y culturales (DESC), al igual que los civiles y políticos, son parte indisoluble de los derechos humanos y del derecho internacional de los derechos humanos, tal como constan en la Declaración Universal, el Pacto Internacional de los Derechos Económicos, Sociales y Culturales, la Declaración Americana de los Deberes y Derechos del Hombre, la Declaración sobre Garantías Sociales, la Convención Americana sobre Derechos Humanos y el Protocolo Facultativo de San Salvador".

Dicha Declaración de Quito, en sus principios generales nos recuerda que:

"13. La fuente de todos los derechos humanos es la dignidad humana. La democracia, la justicia, la paz, el desarrollo y el respeto de los derechos humanos y las libertades fundamentales son conceptos interdependientes que se refuerzan mutuamente.

"14. Los derechos humanos son universales, indivisibles, interdependientes y exigibles, y los DESC tienen el mismo estatuto legal, importancia y urgencia que los derechos civiles y politicos".

A su vez, la Corte Interamericana de Derechos Humanos, al realizar el análisis del artículo 19 referente a los derechos del niño, contenido en el artículo 19 de la Convención Americana sobre Derechos Humanos, precisó:

"En el análisis sobre el posible incumplimiento del Estado de sus obligaciones derivadas del artículo 19 de la Convención Americana, debe tenerse en consideración que las medidas de que habla esta disposición exceden el campo estricto de los derechos civiles y politicos. Las acciones que el Estado debe emprender, particularmente a la luz de las normas de la Convención sobre los Derechos del Niño, abarcan aspectos económicos, sociales y culturales, que forman parte principalmente del derecho a la vida y del derecho a la integridad personal de los niños"4.

\footnotetext{
${ }^{3}$ Afonso Da Silva, José. Impacto da Declaracáo Universal dos Direitos Humanos na Constituicáo Brasileira. En Palomino Manchego, José y Remotti Carbonell, José Carlos (Coordinadores). Derechos Humanos y Constitución en Iberoamérica. Lima, Perú, Ed. Universidad Nacional de San Marcos - Instituto Iberoamericano de Derecho Constitucional (sección peruana). 2002, pp.158-159.

${ }^{4}$ Corte Interamericana de Derechos Humanos, Caso "Instituto de reeducación del menor vs. Paraguay", sentencia de 2 de septiembre de 2004, párrafo 149.
} 


\section{LA AFIRMACIÓN DE QUE TODOS LOS DERECHOS FUNDAMENTALES INDIVIDUALES Y SOCIALES TIENEN SU FUNDAMENTO \\ EN LA DIGNIDAD HUMANA, LA QUE TIENE FUERZA NORMATIVA E IRRADIA TODO EL ORDENAMIENTO JURÍDICO}

La sentencia objeto de análisis, parte razonando acerca de la fuerza normativa que tiene la dignidad de la persona afirmada en el artículo $1^{\circ}$ de la Constitución y que encabeza las Bases de la Institucionalidad, sobre lo cual ya se había pronunciado en diversos fallos anteriores, siendo dicha dignidad el fundamento de cada uno y todos los derechos fundamentales asegurados en el artículo 19 de la Constitución. Asimismo, la dignidad de la persona fundamenta los derechos, los cuales irradian toda la Constitución y todo el ordenamiento jurídico:

"OCTOGÉSIMO QUINTO: Que el artículo primero de la Constitución señala: 'Las personas nacen libres e iguales en dignidad y derechos.' Se trata de una disposición que no sólo encabeza la Carta Fundamental, sino que se irradia en todo su articulado. Consecuentemente, todos los preceptos de la Constitución deben subordinarse a su tenor literal y a su significado.

OCTOGÉSIMO SÉPTIMO: Que, como lo declaró esta Magistratura en causa Rol 1287, 'el sistema institucional vigente en Chile se articula en torno de la dignidad que singulariza a todo sujeto de la especie humana, siendo menester poner de relieve que si la Carta Politica asegura a todas las personas los derechos fundamentales, lo hace en el entendido de que preexisten a ella; y que, en armonía con lo preceptuado en el artículo $5^{\circ}$, inciso segundo, los órganos públicos y los agentes privados, cada cual en ejercicio de la competencia y facultades que les han conferido, respectivamente, la Constitución y la ley, no sólo están obligados a respetar esos derechos, sino que, además, a protegerlos y promoverlos' (considerando decimoctavo);

OCTOGÉSIMO OCTAVO: Que, asimismo, esta Magistratura señaló en dos de los considerandos de su sentencia recaida en la causa Rol 1273 (cuadragésimo quinto y cuadragesimosexto) que la irradiación de la dignidad de la persona hacia todo el articulado de la Constitución presenta una doble dimensión, como principio y como norma positiva. En la misma sentencia el Tribunal razonó en el sentido de que, sin perjuicio de la singularidad sustantiva y procesal de cada disposición constitucional invocada como vulnerada por el mismo precepto bajo actual examen, los derechos en ellas consagrados 'no pueden considerarse de manera aislada o independiente unos de otros. Al contrario, ellos se manifiestan de manera integrada, constituyendo un entramado de normas y principios cuyo alcance no puede apreciarse correctamente sin considerar una visión de conjunto que los incluya a todos ellos y que, también, incorpore su relación a otras disposiciones y valores constitucionales' (considerando cuadragésimo séptimo);”. 


\section{LOS DERECHOS SOCIALES COMO VERDADEROS DERECHOS FUNDAMENTALES}

\section{Y SU FUERZA VINCULANTE DIRECTA}

El Tribunal Constitucional chileno asume la perspectiva que los derechos económicos, sociales y culturales son verdaderos derechos fundamentales al igual que los derechos civiles o individuales, lo que en nuestro ordenamiento positivo es evidente, ya que todos ellos junto con tener fundamento en la misma dignidad humana se encuentran asegurados en la misma disposición constitucional, el artículo 19, a través de sus diversos numerales, todos ellos están protegidos en su contenido esencial por el artículo 19 No 26, como asimismo todos tienen la fuerza normativa que dispone el artículo $6^{\circ}$ del texto constitucional, siendo todos ellos justiciables.

El Tribunal Constitucional chileno ha asumido este reconocimiento pleno de los derechos económicos, sociales y culturales o derechos sociales fundamentales ya en su sentencia del 26 de junio de 2008 :

"Que la amplia mayoría de la doctrina nacional y extranjera reconoce que los derechos sociales, llamados también derechos de prestación o de la segunda generación, son tales y no simples declamaciones o meras expectativas, cuya materialización efectiva quede suspendida hasta que las disponibilidades presupuestarias del Estado puedan Ilevarlos a la práctica"s.

Al efecto, el Tribunal Constitucional en su sentencia Rol N 976 de 2008, ya había precisado que:

"Que resulta ineludible desvanecer la tesis contraria a que los derechos sociales sean realmente tales, aseverando (como lo hace Francisco J. Laporta, cit., pp. 304-305) que poner en duda su 'practicabilidad' de realización, es una idea confusa, porque esa 'reserva de lo posible' lleva a sostener que la Constitución ha de ser 'desactivada', a causa de la imposibilidad económica del Estado de darles satisfacción, convirtiendo asi en virtuales las cláusulas fundamentales que aseguran su materialización;

"Que la naturaleza jurídica de los derechos sociales en el Estado de Derecho Contemporáneo se halla abundante y certeramente configurada, testimonio de lo cual son los pasajes siguientes, extraidos de una obra bien conocida:

'Lo que tienen en común estos derechos no es tanto su contenido, esto es, la esfera de la vida social a que se refieren, sino más bien la posición jurídica que otorgan a su titular. De esta forma, los derechos sociales permitirían a sus titulares exigir ya no abstención por parte del Estado, como sucedía en los derechos de libertad, sino más bien una actuación positiva de

\footnotetext{
${ }^{5}$ Sentencia del Tribunal Constitucional chileno de 26 de junio de 2008, Rol No 976 , considerando vigésimo sexto.
} 
éste en orden a su consecución. Por ello es más adecuado a su naturaleza la denominación de derechos de prestación'. Reencarnación Carmona Cuenca: El Estado Social de Derecho en la Constitución, Consejo Económico y Social, España (2000) p. 150. Abundando en idéntico tópico se ha escrito que los derechos sociales son 'Derechos de prestación (...) que suponen una acción positiva, normalmente de los poderes públicos, aunque también pueden ser los particulares más excepcionalmente, para ayudar a la satisfacción de necesidades básicas, que no pueden ser resueltas por la propia y excesiva fuerza del afectado (...).' Gregorio Peces-Barba Martínez: Curso de Derechos Fundamentales. Teoría General Universidad Carlos III, Madrid (1999) pp. 460;" (').

El Tribunal Constitucional en sus sentencias, roles $\mathrm{No}^{\circ}$ s. 1218 y 1287, en sus respectivos considerandos $20^{\circ}$, reitera categóricamente que los derechos sociales son efectivamente derechos fundamentales "y no simples declamaciones o meras expectativas, cuya materialización efectiva quede suspendida hasta que las disponibilidades presupuestarias del Estado puedan llevarlos a la práctica”.

Esta perspectiva de los derechos sociales como derechos fundamentales con fuerza normativa directa es reforzada en la sentencia analizada, la cual determina:

"NONAGÉSIMO CUARTO: Que en lo concerniente a la presencia de los derechos fundamentales como derecho positivo en Chile, en la más amplia obra de la doctrina nacional sobre la materia (Humberto Nogueira Alcalá: Derechos Fundamentales y Garantías Constitucionales, CECOCH, Santiago de Chile, 2008-2009, tres tomos), el autor señala por una parte: 'La Constitución enuncia los derechos fundamentales asegurados por ella, delimitando los derechos, fijando sus atributos, los elementos subjetivos y objetivos que los identifican' (Tomo 1, p. 86) y, por la otra, en lo que atañe a los derechos a la protección de la salud y a la seguridad social: 'En tal perspectiva, los derechos fundamentales sociales se presentan en el sistema jurídico chileno como principios, reglas y parámetros hermenéuticos del orden constitucional, del mismo nivel jurídico y con la misma eficacia que los derechos civiles y politicos, encontrándose en un mismo articulo constitucional, el artículo 19, fortalecidos por el artículo 5, inciso segundo, de la Carta Fundamental(...) A ello debe agregarse el articulo $6^{\circ}$ de nuestra Constitución, que otorga fuerza normativa y aplicabilidad directa a los enunciados normativos constitucionales, salvo que el propio texto constitucional disponga otra cosa' (Tomo 3, p. 26);".

Como bien señala el Tribunal Constitucional, no pudiendo ser de otra manera, a la luz del artículo $6^{\circ}$ de la Constitución, los derechos fundamentales además de ser derechos subjetivos de las personas, forman parte del ordenamiento jurídico

\footnotetext{
${ }^{6}$ Sentencia del Tribunal Constitucional chileno de 26 de junio de 2008, Rol No 976 , considerandos $27^{\circ}$ y $28^{\circ}$.
} 
constitucional, revestidos de su misma fuerza normativa, por ello el Tribunal Constitucional ha afirmado previamente, en las sentencias roles $\mathrm{No}_{\text {s. }}$ 976, 1218 y 1285 , en sus considerandos 34 del primer fallo y 35 de los siguientes, que:

"no sólo los órganos del Estado deben respetar y promover los derechos consustanciales a la dignidad de la persona humana, sino que esa obligación recae también en los particulares, aunque sea subsidiariamente, puesto que el Código Supremo asegura la intangibilidad de tales atributos en toda circunstancia, cualesquiera sean los sujetos que se hallen en la necesidad de infundir vigencia efectiva a lo proclamado en sus preceptos".

Así, todos los derechos fundamentales, en cuanto componentes objetivos de la Constitución son indivisibles, vinculantes para todos e irradian el conjunto del ordenamiento jurídico nacional, teniendo efectos jurídicos verticales y horizontales, quedando vinculados a ellos no sólo los órganos estatales y sus normas, sino también los particulares y sus actos jurídicos.

\section{LAS OBLIGACIONES DE RESPETO, PROTECCIÓN, PROMOCIÓN Y GARANTÍA DE LOS DERECHOS SOCIALES}

Desde esta perspectiva, puede afirmarse que todos los derechos, tanto los individuales o civiles como los sociales generan obligaciones positivas y negativas al Estado, pudiendo establecerse un esquema de diversos niveles de obligaciones del Estado, entre las cuales están las obligaciones de respeto, las obligaciones de protección, las obligaciones de promoción y las obligaciones de garantía o satisfacción ${ }^{7}$, los cuales constituyen exigencias jurídicas vinculantes determinadas por el Pacto Internacional de Derechos Económicos, Sociales y Culturales de Naciones Unidas, ratificado y vigente en Chile, siendo los atributos que integran tales derechos, especialmente su contenido mínimo y esencial, como sus garantías, elementos que integran el parámetro de control de constitucionalidad, como tácitamente lo sostiene la sentencia analizada, al hacer referencia directa a dicho derecho convencional internacional como a las decisiones y recomendaciones de sus órganos de interpretación y aplicación.

Entre las obligaciones de respeto están las de no afectar con sus acciones la debida protección a la salud de las personas, el derecho a la seguridad social y a las respectivas prestaciones, como asimismo el respeto a la irreversibilidad de los derechos sociales sin justificación, como ha determinado el Comité de Derechos Económicos, Sociales y Culturales de Naciones Unidas.

\footnotetext{
${ }^{7}$ Abramovich, Víctor y Courtis, Christian. El umbral de la ciudadanía. El significado de los derechos sociales en el Estado social constitucional. Editores del Puerto, Buenos Aires, 2006, p. 26.
} 
Entre las obligaciones de protección, se encuentran las de evitar que terceros afecten a través de acciones u omisiones los derechos sociales como no impedir la actividad sindical y el derecho de huelga, el derecho a las prestaciones de salud, las remuneraciones justas, el derecho al descanso, que no se discrimine en el ejercicio de los diversos ámbitos de los derechos sociales, entre otros.

Las obligaciones de promoción, las cuales en el ordenamiento constitucional chileno están expresamente establecidas en el artículo $5^{\circ}$ inciso $2^{\circ}$ de la Constitución, exige realizar todas las acciones positivas para remover los obstáculos sociales, económicos, culturales y políticos que impidan el goce efectivo de los derechos, para lo cual de acuerdo, con el artículo $2^{\circ}$ de la Convención Americana sobre Derechos Humanos, el cual establece la obligación del Estado Parte de "adoptar [...] las medidas legislativas $o$ de otro carácter que fueren necesarias para hacer efectivos tales derechos y libertades".

Las obligaciones de garantía o satisfacción implican asegurar el derecho a las prestaciones mínimas exigidas por la dignidad humana y las obligaciones contenidas en el derecho internacional de los derechos humanos, además del propio texto constitucional: no discriminación, reserva legal, respeto del contenido esencial, entre otros.

\section{LOS DERECHOS SOCIALES COMO OBLIGACIONES}

\section{DE CONDUCTA Y RESULTADO}

El Comité de Derechos Económicos, Sociales y Culturales de Naciones Unidas, afirma, a partir del texto del artículo 2, la existencia para los Estados Partes de obligaciones de conducta y obligaciones de resultado.

La obligación de conducta, tanto activa como pasiva, señala un determinado comportamiento que debe ser realizado por el Estado parte, sus órganos y autoridades, de realizar determinadas acciones o de abstenerse de ellas. Como, por ejemplo, el hecho de que los agentes y autoridades del Estado no pueden desarrollar acciones discriminatorias respecto del ejercicio del derecho a la protección de la salud y del derecho a la seguridad social por parte de hombres y mujeres, debiendo garantizar el acceso a las prestaciones respectivas, como asimismo deben abstenerse de desarrollar conductas convencional y constitucionalmente prohibidas, como son la deslegalización de las regulaciones de los derechos, que vulnera el principio de reserva legal en la materia, o desconocer el contenido esencial de tales derechos.

Los derechos subjetivos a prestaciones, aun cuando no estén suficientemente concretizados, pueden ser invocados judicialmente contra las omisiones inconstitucionales del legislador, como asimismo respecto de la garantía contra su 
deslegalización regulatoria. La fuerza inmediatamente vinculante de los derechos fundamentales, puede y debe ser interpretada, en lo que respecta a los derechos prestacionales, en el sentido de fundamentar originariamente esos derechos y darles un contenido esencial exigible directamente.

La fuerza dirigente y determinante de los derechos económicos, sociales y culturales, como señala Canotlho, invierte, desde luego, el objeto clásico de la pretensión jurídica fundada en un derecho subjetivo individual: "de una pretensión de omisión de los poderes públicos (derecho a exigir que el Estado se abstenga de interferir en los derechos, libertades y garantías) se transita a una prohibición de omisión (derecho a exigir que el Estado intervenga activamente en el sentido de asegurar prestaciones a los ciudadanos", en este caso, de garantizar las prestaciones de salud y de seguridad social.

En este ámbito, consideramos adecuado señalar que los derechos sociales, además de la prohibición de omisión de concreción en su contenido determinado por el bloque constitucional de derechos (aseguramiento de sus atributos y garantías contenidos en las normas constitucionales y del derecho internacional de los derechos humanos vigentes y vinculantes para Chile), establecen la obligación de no dañar el derecho, como la de realizarlo, promoverlo y garantizarlo, como ocurre con el caso de la protección de la salud y la seguridad social.

En esta materia deben tenerse presente las directrices de Maastricht sobre violaciones a los Derechos Económicos, Sociales y Culturales desarrollados bajo el alero de la Comisión Internacional de Juristas entre el 22 y 26 de enero de 1997. En dichas directrices se establecieron las violaciones de derechos mediante actos de comisión y mediante actos de omisión.

Dentro de las violaciones mediante actos de comisión, se señalan las siguientes:

“(a) La anulación o suspensión de cualquier legislación que sea necesaria para seguir ejerciendo un derecho económico, social y cultural que esté vigente en ese momento;

(b) La denegación activa de estos derechos a determinados individuos o grupos mediante cualquier forma de discriminación legislada o impuesta;

(c) El apoyo activo a cualquier medida adoptada por terceros que sea contraria a los derechos económicos, sociales y culturales;

(d) La aprobación de cualquier legislación o politica que sea claramente incompatible con las obligaciones legales preexistentes relativas a estos derechos, salvo cuando esto se hace con el propósito y efecto de aumentar la igualdad y mejorar la realización de los derechos económicos, sociales y culturales de los grupos más vulnerables;

${ }^{8}$ Canotilho. Constitucao Dirigente, ibídem, p. 365. 
(e) La adopción de cualquier medida que sea intencionalmente regresiva y que reduzca el nivel de protección de cualquiera de estos derechos;

(f) La obstaculización o interrupción intencional de la realización progresiva de un derecho previsto en el Pacto, salvo cuando el Estado actúa dentro de los parámetros de una limitación estipulada en el Pacto o debido a la falta de recursos disponibles o fuerza mayor;

(g) La reducción o desviación de un gasto público específico, cuando dicha reducción o desviación resulta de la imposibilidad del goce de estos derechos y no sea acompañada por la adopción de medidas adecuadas que aseguren a todos la subsistencia minima".

Dentro de las violaciones mediante actos de omisión las directrices de Maastricht:

“(a) La no adopción de las medidas adecuadas estipuladas en el Pacto;

(b) La no modificación o revocación de cualquier legislación que sea claramente inconsistente con una obligación prevista en el Pacto;

(c) La no aplicación de legislaciones o ejecución de politicas destinadas a hacer efectivas las disposiciones en el Pacto;

(d) La no regulación de actividades de particulares o grupos para evitar que éstos violen los derechos económicos, sociales y culturales;

(e) La no utilización al máximo de los recursos disponibles para lograr la plena realización de Pacto;

(f) La falta de vigilancia de la efectividad de los derechos económicos, sociales y culturales, incluyendo la elaboración y aplicación de criterios e indicadores para evaluar el acatamiento;

(g) La no eliminación inmediata de los obstáculos que debe eliminar para permitir la efectividad inmediata de un derecho garantizado en el Pacto;

(b) La no aplicación inmediata de un derecho que debe tener efectividad inmediata conforme al pacto;

(i) El no cumplimiento de la norma minima internacional de realización cuando dicho cumplimiento quede dentro de sus posibilidades;

(j) Cuando el Estado, al celebrar convenios bilaterales o multilaterales con otro Estado y con organizaciones internacionales o empresas multinacionales, no tenga en cuenta sus obligaciones legales internacionales en la esfera de los derechos económicos, sociales y culturales".

\section{LOS DERECHOS SOCIALES TIENEN UN CONTENIDO ESENCIAL}

QUE SIEMPRE DEBE SER RESPETADO Y QUE LIMITA LA ACCIÓN

DE LOS ÓRGANOS ESTATALES, INCLUIDO EL LEGISLADOR

Nuestro Tribunal Constitucional ya había asimilado, antes de la sentencia analizada, dicha perspectiva, asumiendo la existencia de un contenido esencial de cada uno y todos los derechos fundamentales, tanto de los derechos individuales 
como de los derechos económicos, sociales y culturales, en su sentencia del 26 de junio de 2008, la que determina: "Que si bien la doctrina y jurisprudencia comparadas han señalado que los derechos sociales requieren la concretización legal de su contenido, también han realzado que la Constitución establece, en relación con ellos, un núcleo esencial, indisponible por el legislador;".

Por otra parte, como se desprende del Pacto Internacional de Derechos Económicos, Sociales y Culturales de Naciones Unidas, la obligación de adopción de medidas inmediatas para la realización de los derechos sociales que exige la utilización del máximo de recursos disponibles, incluyendo la cooperación internacional, además del mínimo no susceptible de afectación en cada derecho forman parte del contenido esencial del derecho, asimismo, las obligaciones básicas o mínimas que exige el Pacto involucran componentes prestacionales específicos, por lo que la exigibilidad no se reduce solamente a obligaciones negativas. En efecto, el Comité, a partir de la Observación General sobre el Derecho a la salud, establece una prohibición absoluta de incumplir las obligaciones básicas que se consideran inderogables. El PIDESC considera que el contenido mínimo de los derechos sociales es inderogable, lo que impide todo incumplimiento en toda circunstancia, constituyendo un mínimo de carácter absoluto que un Estado Parte debe siempre asegurar siendo de cumplimiento inmediato.

En este sentido debemos tener presente la Observación General № 3 del Comité de Derechos Económicos, Sociales y Culturales de la ONU, cuyo párrafo 10, determina que "corresponde a cada Estado Parte una obligación mínima de asegurar la satisfacción de por lo menos niveles esenciales de cada uno de los derechos".

\section{LA JUSTICIABILIDAD DE LOS DERECHOS SOCIALES}

Las concepciones que niegan la justiciabilidad de los derechos económicos, sociales y culturales no son compatibles con las obligaciones de los Estados Partes derivadas del Pacto Internacional de Derechos Económicos, Sociales y Culturales. Sobre la materia el Comité de Derechos Económicos, Sociales y Culturales de Naciones Unidas ha sostenido:

"Aunque sea necesario tener en cuenta el planteamiento general de cada uno de los sistemas juridicos, no hay ningún derecho reconocido en el Pacto que no se pueda considerar que posee en la gran mayoria de los sistemas algunas dimensiones significativas, por lo menos de justiciabilidad. A veces se ha sugerido que las cuestiones que suponen una asignación de recursos deben remitirse a las autoridades politicas y no a los tribunales. Aunque haya que respetar las competencias respectivas de los diversos poderes, es conveniente reconocer

\footnotetext{
${ }^{9}$ Sentencia del Tribunal Constitucional chileno, 26 de junio de 2008, Rol № 976, considerando $30^{\circ}$.
} 
que los tribunales ya intervienen generalmente en una gama considerable de cuestiones que tienen consecuencias importantes para los recursos disponibles. La adopción de una clasificación rígida de los derechos económicos, sociales y culturales que los sitúe por definición, fuera del ámbito de los tribunales sería, por lo tanto, arbitraria e incompatible con el principio de que los dos grupos de derechos son indivisibles e interdependientes. También se reduciría drásticamente la capacidad de los tribunales para proteger los derechos de los grupos más vulnerables y desfavorecidos de la sociedad"10.

En tal sentido, el Comité de Derechos Económicos, Sociales y Culturales, ya había determinado:

"Entre las medidas que cabría considerar apropiadas, además de las legislativas, está la de ofrecer recursos judiciales en lo que respecta a derechos que, de acuerdo con el sistema jurídico nacional, puedan considerarse justiciables. El comité observa, por ejemplo, que el disfrute de los derechos reconocidos, sin discriminación, se fomentará a menudo de manera apropiada, en parte mediante la provisión recursos judiciales y otros recursos efectivos. De hecho, los Estados Parte que son asimismo parte en el Pacto internacional de Derechos Civiles y Politicos ya están obligados (en virtud de los artículos $2^{\circ}$ [párrafo 1 y 3], $3^{\circ}$ y 26 de este Pacto) a garantizar que toda persona cuyos derechos o libertades (inclusive el derecho a la igualdad y a la no discriminación) reconocidos en el presente Pacto hayan sido violados 'podrá interponer un recurso efectivo' (apartado a del párrafo 3 del artículo $2^{\circ}$ ). Además, existen en el Pacto Internacional de Derechos Económicos, Sociales y Culturales varias otras disposiciones, entre ellas los artículos 3, $7^{\circ}$ (inciso i) del apartado a, $8^{\circ}, 10$ (párrafo 3), 13 (apartado a del párrafo 2 y párrafos 3 y 4) y 15 (párrafo 3), que cabría considerar de aplicación inmediata por parte de los órganos judiciales y de otra indole en numerosos sistemas legales nacionales. Parecería difícilmente sostenible sugerir que las disposiciones indicadas son intrinsecamente no autoejecutables"11.

El Comité de Derechos Económicos, Sociales y Culturales de Naciones Unidas, en su Observación General N 9, ha precisado:

"[...] A este respecto, es importante distinguir entre justiciabilidad (que se refiere a las cuestiones que pueden o deben resolver los tribunales) y las normas de aplicación inmediata (que permiten su aplicación por los tribunales sin más disquisiciones). Aunque sea necesario tener en cuenta el planteamiento general de cada uno de los sistemas jurídicos, no hay ningún derecho reconocido en el Pacto que no se pueda considerar que posee en la gran mayoría de los sistemas algunas dimensiones significativas, por lo menos de justiciabilidad. A veces se ha sugerido que las cuestiones que suponen una asignación de recursos

${ }^{10}$ Observación General Nº 9, E/C. 12/1998/24, 3 de diciembre de 1998.

${ }^{11}$ Observación General 3, "La índole de las obligaciones de los Estados Parte", 1990, párrafo 5. 
deben remitirse a las autoridades políticas y no a los tribunales. Aunque haya que respetar las competencias respectivas de los diversos poderes, es conveniente reconocer que los tribunales ya intervienen generalmente en una gama considerable de cuestiones que tienen consecuencias importantes para los recursos disponibles. La adopción de una clasificación rígida de los derechos económicos, sociales y culturales que los sitúe, por definición, fuera de los ámbitos de los tribunales sería, por lo tanto, arbitraria e incompatible con el principio de que los grupos de derechos son indivisibles e interdependientes. También se reduciría drásticamente la capacidad de los tribunales para proteger los derechos de los grupos más vulnerables y desfavorecidos de la sociedad"12.

\section{El Tribunal Constitucional pasa a Razonar sobre los Derechos}

ESPECÍFICOS QUE LAS DISPOSICIONES LEGALES CUESTIONADAS PUEDEN HABER

VULNERADO. EL PRIMER DERECHO FUNDAMENTAL EXAMINADO COMO PARTE DEL PARÁMETRO DE CONTROL DE CONSTITUCIONALIDAD ES LA IGUALDAD ANTE LA LEY,

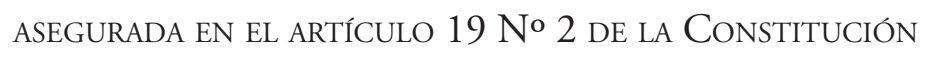

11.1. En esta perspectiva, el Tribunal Constitucional asume los criterios ya pacíficos en el ámbito de la jurisdicción constitucional europea y latinoamericana, sobre igualdades y desigualdades esenciales:

"CENTÉSIMO: Que en el fallo Rol 1273, recaído en causa de inaplicabilidad por inconstitucionalidad que sirve de sustento al procedimiento de autos, esta Magistratura incorporó en su entendimiento sobre la igualdad los criterios jurisprudenciales que en el derecho comparado se han utilizado en la última década para afrontar las crecientes complejidades que presentan los casos sobre tal garantía constitucional, asi como los afanes desplegados por la doctrina en la misma dirección. De estos aportes, entre otros descritos en la sentencia citada, destaca el enfoque alemán que distingue conceptualmente entre 'igualdades esenciales' y 'desigualdades esenciales', de tal modo que estamos en presencia de una igualdad esencial cuando 'personas, grupos de personas o situaciones, sobre la base de un punto de partida (tertium comparationis), son comparables', de lo que, consecuentemente, el Tribunal Constitucional Federal alemán ha decidido que la Ley Fundamental considera arbitrario y, por ende, inconstitucional, tratar desigualmente a las igualdades esenciales, así como tratar igualmente a las desigualdades esenciales. Además, se agrega la denominada 'nueva fórmula', consistente en considerar lesionada la igualdad ante la ley cuando un grupo de destinatarios de la norma, comparados con otro grupo de destinatarios de la norma, son tratados de manera distinta, a pesar de que entre ambos grupos no media ninguna diferencia de tal entidad o importancia que pudiera justificar

\footnotetext{
${ }^{12}$ Comité de Derechos Económicos, Sociales y Culturales de Naciones Unidas, en su Observación General № 9. "La aplicación interna del Pacto". 1998. Párrafo 10.
} 
un tratamiento desigual. Para poder dimensionar tales situaciones, esta fórmula requiere expresamente una ponderación en el sentido de examen de proporcionalidad, especialmente respecto de una diferencia de trato de gran intensidad, para lo cual se requiere que aquélla persiga un fin legitimo, que esa buisqueda sea necesaria y que presente una razonable relación con el valor del fin propuesto;".

11.2. Sobre la materia cabe recordar que la Corte Interamericana de Derechos Humanos ha establecido la necesidad de aplicar el principio de proporcionalidad siempre que se establezcan restricciones legales al ejercicio de derechos fundamentales, así ha determinado que:

"La necesidad de las restricciones legalmente contempladas dependerá de que estén orientadas a satisfacer un interés público imperativo, siendo insuficiente que se demuestre, por ejemplo, que la ley cumple un propósito útil u oportuno. La proporcionalidad radica en que la restricción debe ajustarse estrechamente al logro de un legitimo objetivo, interfiriendo en la menor medida posible en el efectivo ejercicio del derecho restringido. Finalmente, para que sean compatibles con la Convención las restricciones deben justificarse según objetivos colectivos que, por su importancia, preponderen claramente sobre la necesidad del pleno goce del derecho restringido" 13 .

11.3. A su vez, la sentencia objeto de análisis recuerda la reforma constitucional de 1999, que incorporó expresamente en el artículo 19 No 2 de la Constitución la igualdad de hombres y mujeres ante la ley, con el objeto de armonizar el texto constitucional con la Convención de las Naciones Unidas sobre la Eliminación de Todas las Formas de Discriminación contra la Mujer:

“CENTÉSIMO PRIMERO: Que la expresión 'hombres y mujeres son iguales ante la ley' que la Carta introdujo en la última parte del numeral $2^{\circ}$ de su artículo 19, encontró su consagración constitucional en 1999, dando cuenta su historia fidedigna de la envergadura de tal reforma constitucional, asi como del contexto cultural y jurídico, nacional e internacional, en el que se aprobó".

11.4. El Tribunal Constitucional asume la obligación contenida en la Convención sobre no discriminación de la mujer, en materia de salud, como la obligación de establecer la igualdad de acceso a las atenciones de salud con los hombres, atributos y garantías que el Tribunal Constitucional integra al parámetro de control de constitucionalidad para determinar el juicio de constitucionalidad de las disposiciones legales cuestionadas:

\footnotetext{
${ }^{13}$ Corte Interamericana de Derechos Humanos. Caso "Comunidad Indígena Yakse Axa c. Paraguay". Sentencia de 17 de junio de 2005, párrafo. 145.
} 
"CENTÉSIMO TERCERO: Que el artículo 12.1 de la citada Convención señala: 'Los Estados Parte adoptarán todas las medidas apropiadas para eliminar la discriminación contra la mujer en la esfera de la atención médica a fin de asegurar, en condiciones de igualdad entre hombres y mujeres, el acceso a servicios de atención médica, inclusive los que se refieren a la planificación de la familia'. A su vez, la Observación General 16, del Comité de Derechos Económicos, Sociales y Culturales de Naciones Unidas, aprobada en Ginebra en el $34^{\circ}$ periodo de sesiones del 25 de abril al 13 de mayo de 2005, se refiere a la igualdad de derechos del hombre y la mujer al disfrute de los derechos económicos, sociales y culturales (artículo 3 del Pacto Internacional de Derechos Económicos, Sociales y Culturales)'”.

11.5. Asimismo, el Tribunal Constitucional asume un test de escrutinio constitucional fuerte respecto de las disposiciones legales que establezcan las diferencias de trato entre hombres y mujeres, de acuerdo al principio de proporcionalidad:

"CENTÉSIMO QUINTO: Que todo lo señalado respecto de la prohibición de discriminación entre hombres y mujeres no significa que el ordenamiento jurídico no pueda establecer diferencias entre ambos sexos. La igualdad entre hombres y mujeres no puede ser absoluta, incluso para resguardar el propio beneficio de la mujer. Como lo señala un reciente estudio: 'el legislador puede establecer diferencias entre los hombres y las mujeres en el contenido de las normas, siempre y cuando existan diferencias reales y efectivas que discriminen a uno de los sexos en ámbitos concretos de la realidad vital; y significa también que el legislador no puede establecer diferencias únicamente en razón del sexo. El ser hombre o el ser mujer, o las diferencias que otrora existieron entre los sexos, no pueden ser susceptibles de diferencias en el contenido de la norma, pues el sexo no constituye per se una diferencia objetiva ni razonable, como tampoco son objetivas y razonables las diferencias pasadas que existieron entre hombres y mujeres en ámbitos concretos de la realidad vital'. (Cristina Zoco Zabala: Igualdad de género en la nueva normativa nacional y estatutaria a la luz de las innovaciones del ordenamiento comunitario, en: Revista Aragonesa de Administración Pública, 30, junio de 2007, p. 255);”.

11.6. El Tribunal Constitucional refuerza su perspectiva, recordando los criterios sobre igualdad entre hombres y mujeres en materia de derechos sociales, especialmente en materia de prestaciones de salud, que utiliza el Consejo de la Unión Europea:

"CENTÉSIMO SEXTO: Que la igualdad jurídica entre hombres y mujeres tiene expresiones muy concretas en el goce de los derechos sociales, del derecho a la saludy, especificamente, en lo relativo a las prestaciones de salud, incluyendo los denominados seguros de salud. En el ámbito comunitario europeo, el Consejo de la Unión Europea adoptó un acuerdo, en 
diciembre de 2004, sobre la ampliación de la igualdad de trato entre hombres y mujeres al acceso de bienes y servicios y a su suministro, en el que se lee, en relación a la cuestión de autos: 'Su ámbito incluye los seguros y actividades financieras conexas siempre que sean privadas, voluntarias y ajenas a la relación laboral. En este contexto, la igualdad de trato es un principio rector, por lo cual la inclusión del sexo como factor actuarial no debería dar pie a diferencias entre las primas y las prestaciones de los seguros', agregándose: 'En cualquier caso, los costes relacionados con el embarazo y la maternidad no deberán crear diferencias en las primas y prestaciones' (Consejo de la Unión Europea, Comunicado de prensa c104/350, Bruselas, 13 de diciembre de 2004);".

11.7. Luego, el Tribunal Constitucional analiza las disposiciones cuestionadas del artículo 38 ter de la Ley $\mathrm{N}^{\circ} 18.933$, razonando sobre si las distinciones de sexo y las diferencias por rangos de edad establecidos por la normativa legal son justificables constitucionalmente a la luz de los principios de razonabilidad y proporcionalidad:

“CENTÉSIMO OCTAVO: Que el artículo 38 ter de la Ley $N^{\circ} 18.933$ incluye, en su inciso segundo, tres tipos de diferenciaciones o criterios para que las tablas de factores determinen los tipos de beneficiarios: sexo, condición de cotizante o carga y los rangos de edad;

CENTÉSIMO NOVENO: Que de entre los tres criterios enunciados, debe distinguirse sexo y edad, por una parte, y condición de cotizante o carga, por la otra. Mientras que esta uiltima obedece a una situación en la que cada persona se coloca contractualmente en el marco de la autonomía de la voluntad, el sexo y la edad son factores cuya existencia y evolución transcurren independientemente de la voluntad de las personas. Según el Diccionario de la Lengua Española, sexo significa 'condición orgánica que distingue al macho de la hembra en los seres humanos, en los animales y en las plantas', mientras que edad significa 'tiempo que ha vivido una persona o ciertos animales y vegetales'. Ambas expresiones, por lo tanto, denotan estados naturales, inimputables a las personas que los viven, especialmente para ser afectados negativamente por la ley;".

11.8. Hay así, en materia de sexo y edad, una distinción sospechosa de inconstitucionalidad que debe ser examinada en conjunto con los atributos y garantías de los derechos a la protección de la salud y del derecho a la seguridad social en el texto constitucional y el derecho internacional de los derechos humanos vinculante para Chile:

"CENTÉSIMO DECIMOTERCERO: Que el derecho a la protección de la salud, como está formulado en la Constitución chilena, se encuentra profundamente enraizado en una serie de convenciones internacionales vigentes y contraidas por Chile. Desde luego el Pacto Internacional de Derechos Económicos, Sociales y Culturales de Naciones Unidas, cuyo Comité está encargado de presentar informes periódicos sobre el estado de cumplimiento de 
los diferentes derechos consagrados en el Pacto. Este Comité del mencionado Pacto interpreta el derecho a la salud como un derecho de contenido complejo que engloba no sólo el derecho a una asistencia sanitaria oportuna y adecuada, sino que también se extiende a los determinantes básicos de la salud, tales como el acceso al agua potable y al saneamiento, la vivienda adecuada, el suministro adecuado de alimentos sanos, las condiciones saludables de trabajo y medio ambiente, etc.'. 'El derecho a la salud debe entenderse como el derecho al disfrute de toda una gama de facilidades, bienes, servicios y condiciones necesarios para alcanzar el más alto grado de salud' (Juan Ma. Pemán Marin: El derecho a la salud como derecho social. Desarrollos recientes desde la perspectiva internacional y en el derecho comparado, en: Revista de Administración Pública, 179, Madrid, 2009, p. 50);”.

\section{El Tribunal Constitucional examina las obligaciones del Estado RESPECTO DEL DERECHO A LA PROTECCIÓN DE LA SALUD Y DEL DERECHO A LA SEGURIDAD SOCIAL QUE ESTABLECE LA CONSTITUCIÓN}

"CENTÉSIMO DECIMOCUARTO: Que los principales derechos sociales que la Constitución asegura a todas las personas son configurados a partir de la posibilidad de acceder a una determinada prestación. Asi sucede con el derecho a la protección de la salud, en que se debe proteger 'el libre e igualitario acceso a las acciones' (artículo 19, $N^{\circ} 9^{\circ}$ ); lo mismo sucede con el derecho a la seguridad social, en que la acción del Estado debe estar dirigida 'a garantizar el acceso de todos los habitantes al goce de prestaciones' (artículo $19, N^{\circ} 18^{\circ}$ );

CENTÉSIMO DECIMOQUINTO: Que la Constitución garantiza el acceso a dichas prestaciones asignándole roles al Estado y a los particulares;

CENTÉSIMO DECIMOSEXTO: Que la Ley Fundamental le asigna al Estado un rol de control o supervigilancia. Asi, establece que al Estado le corresponde el 'control de las acciones relacionadas con la salud' (artículo 19, $N^{\circ} 9^{\circ}$ ) y, tratándose del derecho a la seguridad social, dispone que 'el Estado supervigilará el adecuado ejercicio del derecho a la seguridad social' (artículo 19, $N^{\circ} 18^{\circ}$ );

CENTÉSIMO DECIMOSÉPTIMO: Que, a su vez, la Constitución le garantiza a los particulares el derecho a elegir que las prestaciones les sean entregadas por entidades estatales o por entidades privadas. Asi, en el derecho a la salud esto se expresa en que 'cada persona tendrá el derecho a elegir el sistema de salud al que desee acogerse' (artículo 19, $N^{\circ} 9^{\circ}$ ). Por otra parte, la Carta Fundamental garantiza que no exista monopolio prestacional del Estado. Estas prestaciones, entonces, pueden ser entregadas por instituciones públicas o privadas' (artículo $19, N^{\circ}$ s. $9^{\circ}$ y $18^{\circ}$ );

CENTÉSIMO DECIMOCTAVO: Que, tratándose del derecho a la salud, la Constitución va más allá, pues establece el 'deber preferente del Estado de garantizar la ejecución de las acciones de salud'. Esta expresión es utilizada únicamente en este derecho (Silva Bascuñán, Alejandro; Tratado de Derecho Constitucional, Tomo XII, Editorial Jurídica de Chile, 
Santiago, 2008, p. 140); la Constitución no califica de igual manera otros deberes del Estado (Bulnes Aldunate, Luz; El derecho a la protección de la salud en la Constitución de 1980; en Gaceta Jurídica N²94, diciembre, 2004, p. 18);".

"CENTÉSIMO VIGÉSIMO SEGUNDO: Que, a continuación, la Constitución utiliza la expresión 'garantizar'. Con ello, se apunta a dar seguridad o certeza de que se ejecuten las pertinentes acciones de salud (Silva Bascuñán, A.; ob. cit., p. 140). Para el profesor Cea Egaña, se busca 'asegurar o dar certeza, a cualquier titular del derecho, que las acciones de salud le serán proporcionadas, sin discriminación, cuando necesite acceder a una o más de ellas' (ob. cit., p. 310). Se pretende que todo titular del derecho, sin diferencias arbitrarias, podrá efectivamente gozar de las prestaciones de salud (Nogueira Alcalá, $H$.; ob. cit., p. 127);".

\section{Respecto DEL ASEGURAMIENTO DEL DERECHO A LA SEGURIDAD SOCIAL, EL} TRIBUNAL CONSTITUCIONAL RAZONA SOBRE LA SOLIDARIDAD COMO ELEMENTO ESENCIAL DE LOS ATRIBUTOS DEL DERECHO A LA SEGURIDAD SOCIAL, A PARTIR DE UNA INTERPRETACIÓN SISTEMÁTICA DEL TEXTO CONSTITUCIONAL Y SU ARMONÍA CON LAS DISPOSICIONES DE LAS CONVENCIONES INTERNACIONALES SOBRE LA MATERIA

"CENTÉSIMO TRIGÉSIMO: Que, sin embargo, como lo ha sostenido esta Magistratura: la supresión, en el texto del artículo 19, $N^{\circ} 18^{\circ}$, de la Constitución, de los principios rectores de la Seguridad Social, incluidos en el inciso tercero del numeral 21 del artículo 1 del Acta Constitucional No 3, carece de relevancia, pues tales principios configuran la esencia de aquel derecho, de modo que se entienden siempre absorbidos por él, pues de lo contrario perdería su identidad especifica' (Sentencia Rol 1218, C. 30');

CENTÉSIMO TRIGÉSIMO PRIMERO: Que el contenido esencial de la seguridad social se revela en una interpretación sistemática del texto constitucional en el que se recogieron los principios de solidaridad, universalidad, igualdad y suficiencia y unidad o uniformidad, sobre todo si se ven conjuntamente el derecho a la salud (artículo 19, $\left.N^{\circ} 9^{\circ}\right)$ y el derecho a la seguridad social (artículo 19, $N^{\circ} 18^{\circ}$ ). Así, en primer lugar, el principio de solidaridad se expresa en el deber que tiene el Estado, es decir, la comunidad politicamente organizada, de garantizar económicamente el goce de estos derechos. Las expresiones de la Constitución son claras en este sentido, toda vez que se obliga al Estado a 'garantizar' el goce de los derechos; asimismo, se faculta al legislador para establecer cotizaciones obligatorias (numerales $9^{\circ}$ y $18^{\circ}$ del artículo 19 de la Constitución); CENTÉSIMO TRIGÉSIMO SEGUNDO: Que, por otra parte, la Constitución incorpora el principio de universalidad subjetiva, pues estos derechos se encuentran asegurados a todas las personas, sin distinciones de ninguna especie. La expresión 'todas las personas' no sólo forma parte del encabezado del artículo 19 constitucional, sino que se refleja en el uso de los términos 'cada persona', que utiliza su numeral 9o, 'prestaciones básicas uniformes' y 'todos los habitantes', contenidos en su numeral 18\%; 
CENTÉSIMO TRIGÉSIMO TERCERO: Que también la Constitución acoge el principio de universalidad objetiva, pues asegura estos derechos a las personas frente a un rango amplio de riesgos individuales. En el derecho a la protección de la salud se otorgan 'acciones de promoción, protección y recuperación de la salud y de rehabilitación del individuo' y la 'ejecución de las acciones de salud' (artículo 19, $N^{\circ} 9^{\circ}$ ). En el derecho a la seguridad social, se asegura 'el acceso de todos los habitantes al goce de prestaciones básicas uniformes' (artículo 19, $N^{o} 18^{\circ}$ );

CENTÉSIMO TRIGÉSIMO CUARTO: Que nuestra Constitución, a su vez, establece claramente que las prestaciones que envuelven los derechos en cuestión han de ser igualitarias y suficientes, sea que se otorguen por el Estado o por agentes privados. Las expresiones que en tal sentido emplea el texto constitucional son: 'libre e igualitario acceso' (artículo 19, $N^{\circ} 9^{\circ}$ ) y 'prestaciones básicas uniformes' (artículo 19, $N^{\circ} 18^{\circ}$ ). Por su parte, por mandato de la misma Carta Fundamental, el Estado debe 'garantizar' los derechos (artículo 19, $N^{o} 9^{\circ}$, inciso cuarto, y $N^{o} 18^{\circ}$, inciso tercero) y/o 'supervigilar' (artículo 19, $N^{\circ} 18^{\circ}$, inciso cuarto), o incluso 'coordinar y controlar' (artículo 19, No 90);".

13.1. Es importante resaltar la argumentación del Tribunal Constitucional de que la edad no debe ser un elemento de discriminación en sistemas de seguridad social, siendo el envejecimiento un factor que debe ser garantizado por el sistema de seguridad social.

"CENTÉSIMO TRIGÉSIMO SEXTO: Que la vinculación estrecha entre el derecho a la protección de la salud y el derecho a la seguridad social se ve manifestada en los propósitos de los sistemas de seguridad social, que son los de asegurar a sus beneficiarios 'condiciones de vida ante la ocurrencia de riesgos como la desocupación, la vejez, la incapacidad, entre otros, que les impiden a quienes los experimentan obtener, mediante el trabajo, los medios indispensables para su subsistencia o la de su grupo familiar. (Mario Verdugo, Emilio Pfeffer y Humberto Nogueira: Derecho Constitucional, Editorial Jurídica de Chile, 1997, Tomo I, p. 210).

Como se observa, el factor edad es constituyente de ambas garantías, resultando incompatible con sus respectivos propósitos el que la desprotección frente a los estados de necesidad aumente en la misma medida en que aumentan los años de vida;

CENTÉSIMO TRIGÉSIMO SÉPTIMO: Que, a mayor abundamiento, la relación entre el derecho a la seguridad social y el derecho a la protección de la salud se ha visto expresada en las consagraciones jurídicas internacionales, como en el Convenio $N^{\circ} 102$ de la Organización Internacional del Trabajo (OIT), que incluye como 'riesgos y contingencias sociales en el ámbito de su protección: enfermedad, maternidad, vejez, invalidez, muerte, cesantía o desempleo, cargas familiares y riesgos profesionales' (citado en: Gobierno de Chile, MINSEGPRES: Doctrina Constitucional del Presidente Ricardo Lagos Escobar (2000-2006), LOM, Santiago de Chile, 2010, Tomo I, p. 223);”. 


\title{
14. El Tribunal Constitucional desarrolla
}

\author{
EL RAZONAMIENTO JURÍDICO PERTINENTE EN UN TEST ESTRICTO DE \\ CONSTITUCIONALIDAD APLICANDO LOS PRINCIPIOS DE RAZONABILIDAD Y DE \\ PROPORCIONALIDAD RESPECTO DE LA IGUALDAD ANTE LA LEY
}

“CENTÉSIMO CUADRAGÉSIMO TERCERO: Que, consecuentemente con el método descrito, en el caso de autos esta Magistratura ha examinado si el artículo 38 ter de la Ley $N^{o}$ 18.933, objeto de este proceso constitucional: a) cumple con ser adecuado a los fines constitucionales de tutelar la igualdad ante la ley, especialmente entre hombres y mujeres, de proteger la salud de las personas incorporadas al sistema privado de salud en el cual actúan las Instituciones de Salud Previsional, especialmente en lo que concierne al rol preferente del Estado en garantizar la ejecución de las acciones de salud y en proteger el libre e igualitario acceso a ellas de todas esas personas, y de asegurar que las personas accedan al goce de las de prestaciones básicas uniformes de seguridad social, garantizadas por la acción del Estado; b) cumple con ser indispensable para alcanzar los fines señalados; y c) si guarda proporcionalidad con tales objetivos;

CENTÉSIMO CUADRAGÉSIMO CUARTO: Que, como corolario del análisis efectuado, este Tribunal ha logrado convicción en cuanto a que los números 1, 2, 3 y 4 del inciso tercero del artículo 38 ter de la Ley $N^{\circ} 18.933$ no cumplen los supuestos descritos en el considerando precedente $y$, por consiguiente, son incompatibles con el derecho a la igualdad ante la ley, especialmente entre hombres y mujeres, y lesionan, asimismo, el derecho a la protección de la salud y el derecho a la seguridad social, en el sentido que todos ellos se encuentran reconocidos y asegurados en nuestra Carta Fundamental;".

14.1. El fallo del Tribunal Constitucional determina que el artículo 38 ter de la Ley No 18.933, en lo referente a la tabla de factores, éstos constituyen criterios discriminatorios, afectando igualdades esenciales, como asimismo, es contraria a la Constitución la aplicación de dicha tabla de factores para modificar los precios de los planes de salud, siendo desproporcionados e irrazonables, por tanto discriminatorios, lo que determinan su inconstitucionalidad por afectar el derecho a la igualdad ante la ley:

"CENTÉSIMO CUADRÁGESIMO QUINTO: Que, en primer lugar, es dable observar que si bien las diferencias fundadas en los criterios de la edad y del sexo de las personas, no son, en si mismas, jurídicamente reprochables, ni tampoco prima facie arbitrarias, siempre que respondan a una fundamentación razonable, sí lo son aquellas que se derivan de dichos preceptos. En efecto, los numerales 1, 2, 3 y 4 del inciso tercero del artículo 38 ter de la Ley $N^{\circ} 18.933$ son contrarios a la igualdad ante la ley asegurada en el numeral $2^{\circ}$ del artículo 19 de la Carta Fundamental, toda vez que admiten el establecimiento de diferencias arbitrarias al no instituir limites idóneos, necesarios, proporcionados y, por ende, razonables, respecto del ejercicio de la potestad discrecional que el mismo precepto 
legal le entrega a la Superintendencia del ramo para determinar, a través de instrucciones de general aplicación', los topes de edad, dentro de la estructura de las tablas de factores que, a su vez, deben utilizar las Isapres al elaborar los planes de salud que ofrezcan a sus afliados y para determinar la manera cómo influirá en la variación del precio de tales contratos el aumento o la reducción del factor que corresponda a un beneficiario del respectivo plan en razón de su edad;

CENTÉSIMO CUADRAGÉSIMO SEXTO: Que, a mayor abundamiento, como ya constató esta Magistratura -considerandos sexagésimo primero y sexagésimo segundo de esta sentencia-y lo reconoció el señor Presidente de la República en el informe evacuado en este proceso-principalmente en la afirmación que formula la autoridad a fojas 91, con letra destacada, en el punto 3.7. del Capitulo IV del documento-, resulta desproporcionada y carente de razonabilidad la norma contenida en el artículo segundo transitorio de la Ley $N^{o} 20.015$, y con apoyo en el mismo juicio jurídico debe estimarse inconstitucional la parte del articulado permanente de la ley en examen que entrega amplia libertad de actuación a un organismo de la Administración en los términos señalados, ya que esa clase de disposiciones se aparta de la razonabilidad que debe presidir la regulación de los derechos fundamentales, como lo recuerdan la doctrina y la jurisprudencia citadas en el cuerpo de este fallo;

CENTÉSIMO CUADRAGÉSIMO OCTAVO: Que, además, como lo ha señalado esta Magistratura en sentencias recientes -roles 1273 y 1348-, la diferenciación por sexo y edad que permite el artículo 38 ter de la Ley $N^{\circ} 18.933$, establece un trato desigual para igualdades esenciales, como son: i) la igualdad en dignidad y derechos con que las personas nacen (inciso primero del artículo $1^{\circ}$ de la Constitución), ii) la igualdad de oportunidades como derecho de las personas en la participación en la vida nacional (inciso quinto del artículo $1^{\circ}$ de la Ley Fundamental), iii) la igualdad ante la ley entre el hombre y la mujer (oración final del inciso primero del número $2^{\circ}$ del artículo 19 de la Constitución), y iv) la igualdad de acceso a las acciones de salud (inciso segundo del número $9^{\circ}$ del artículo 19 de la Constitución);".

Así, el Tribunal Contitucional determina la inconstitucionalidad de los preceptos legales cuestionados por afectar las igualdades básicas de los derechos a la protección de la salud (inciso $2^{\circ}$ y final del No 9 del artículo 19) y las prestaciones de seguridad social (artículo 19 No 18), cuyos "principios rectores son la universalidad (subjetiva y objetiva), la integridad o suficiencia, la solidaridad y la unidad del sistema de seguridad social", así dicho precepto obliga al Estado a asegurar el acceso de todos los habitantes al goce de prestaciones básicas uniformes y a supervigilar el adecuado ejercicio de ese derecho; dicha uniformidad exigida por la Constitución resulta vulnerada si el costo de las cotizaciones para la asegurada por el disfrute de unas mismas prestaciones, se ve acrecentado por el mero hecho de progresar en edad, por una decisión unilateral de la respectiva ISAPRE, lo que al mismo tiempo produce, como natural efecto, el menoscabo del ejercicio ade- 
cuado de su derecho a la seguridad social, como la eventual expulsión del sistema de salud que éste eligió y pagó hasta su vejez, el cual está fijado en unidades que se reajustan automáticamente.

\section{El legislador no PUede deslegalizar materias QUe la Constitución DETERMINA QUE SÓLO EL LEGISLADOR PUEDE REGULAR}

El Tribunal Constitucional constata que la Constitución no posibilita al legislador deslegalizar materias que únicamente el legislador puede regular de acuerdo el artículo 19 No 9 la Constitución, lo que produce la inconstitucionalidad del artículo segundo transitorio de la Ley $\mathrm{N}^{\circ} 20.015$ al entregarle a la Superintendencia del ramo, la determinación permanente -específicamente en el numeral 4 del inciso tercero del artículo 38 ter- de la relación máxima entre el factor de edad más bajo y el más alto de cada tabla, diferenciada por sexo:

"CENTÉSIMO CUADRAGÉSIMO NOVENO: Que, en segundo lugar, en relación al derecho a la protección de la salud, debe señalarse que una misma materia no puede ser regulada indistintamente por la ley y por normas administrativas y que, en consecuencia, no le corresponde al legislador legalizar o deslegalizar materias, pues eso lo define el constituyente;

CENTÉSIMO QUINCUAGÉSIMO: Que, como ya se ha señalado, mientras el artículo segundo transitorio de la Ley $N^{\circ} 20.015$ estableció, por el plazo de 10 años contados desde la entrada en vigencia de dicha legislación, la relación máxima entre el factor de edad más bajo y el más alto de cada tabla, diferenciada por sexo, señalando que ésta iba a ser de hasta 9 veces, en el caso de las mujeres, y de hasta 14 veces, en el caso de los hombres, el número 4 del inciso tercero del artículo 38 ter de la Ley No 18.933 le entregó tal defnición a la Superintendencia del ramo;

CENTÉSIMO QUINCUAGÉSIMO PRIMERO: Que si el legislador, en el año 2005, fijó en el citado precepto transitorio la determinación de tales márgenes en el entendido de que éstos se hallan dentro de las 'materias básicas' de la seguridad social, él mismo vulneró la Constitución al entregarle su definición a un organismo regulador, esto es, a la Superintendencia del ramo, en la determinación permanente-especificamente en el numeral 4 del inciso tercero del artículo 38 ter bajo control-;

CENTÉSIMO QUINCUAGÉSIMO TERCERO: Que, en efecto, dichos preceptos permiten la operación de un complejo mecanismo de reajustabilidad del precio de los planes de salud que se ofrecen en el sector privado. Así, el precio final del plan de salud que debe pagar el afiliado a una Isapre se determina multiplicando el precio base por el respectivo factor de edad que corresponda al afiliado o a alguno de los beneficiarios, de conformidad a la respectiva tabla de factores (artículo 170, letra m), del D.F.L. $N^{\circ} 1$, de Salud, 2005). Por otra parte, el plan de salud es elaborado por la Isapre, la estructura de la tabla de factores es definida por la Superintendencia a través de instrucciones y los factores de cada tabla son libremente determinados por la Isapre. A través de este mecanismo, 
en consecuencia, no se han fijado directamente por la ley 'las condiciones' que le manda establecer la Constitución para garantizar el acceso a la prestación, sino que lo que ha hecho el legislador es dispersar la determinación de tales condiciones en distintos actores. Resulta claro, además, que en tal esquema el papel del afiliado, que es el actor principal del derecho a la protección de la salud, prácticamente desaparece, pues queda constreñido a aceptar o a rechazar lo que la entidad previsional le ofrezca;".

\section{El Tribunal Constitucional determina la inconstitucionalidad de los} CUATRO NUMERALES DEL INCISO TERCERO DEL ARTÍCULO 38 TER POR NO DAR CUMPLIMIENTO AL DEBER DE FIJAR LAS CONDICIONES DEL DEBER PREFERENTE DEL ESTADO DE GARANTIZAR LAS ACCIONES DE SALUD

“CENTÉSIMO QUINCUAGÉSIMO SEGUNDO: Que los primeros cuatro numerales del inciso tercero del artículo 38 ter tampoco cumplen lo dispuesto en el inciso cuarto del numeral $9^{\circ}$ del artículo 19 de la Carta Fundamental, en orden a fijar 'las condiciones' del deber preferente del Estado de garantizar la ejecución de las acciones de salud y, por consiguiente, son inconstitucionales;".

17. El Tribunal Constitucional precisa que los seguros privados de salud EN CUANTO AFECTAN EL DERECHO A LA SEGURIDAD SOCIAL Y EL DERECHO A LA PROTECCIÓN DE LA SALUD TIENEN CARÁCTER DE ORDEN PÚBLICO, NO ALTERABLES UNILATERALMENTE POR ISAPRES, NI DESPROPORCIONADAMENTE “CENTÉSIMO QUINCUÁGESIMO CUARTO: Que, en este mismo orden de consideraciones, resulta imprescindible indicar que el contrato que celebra un afiliado con una determinada Isapre no equivale a un mero seguro individual de salud, regido por el principio de autonomía de la voluntad, pues opera en relación con un derecho garantizado constitucionalmente a las personas en el marco de la seguridad social y en que la entidad privada que otorga el seguro, tiene asegurada, por ley, una cotización, o sea, un ingreso garantizado. Así, las normas que regulan esta relación jurídica son de orden público;

CENTÉSIMO QUINCUAGÉSIMO QUINTO: Que, por otra parte, el mecanismo de reajustabilidad que opera en este ámbito material es exponencial, pues implica que el precio base del plan se multiplica por el factor determinado en su tabla y, de esta forma, se permite un reajuste indefinido. En efecto, de la regulación contenida en las disposiciones bajo examen se puede concluir que la ley no ha establecido condiciones o parámetros razonables, ya que permite que el precio por el seguro de salud contratado con la Isapre aumente en una dimensión que puede ser equivalente a la confiscación de las rentas de un afiliado.

El seguro de salud que opera en este ámbito tiene por objeto garantizar el acceso a las prestaciones de salud. Por lo mismo, precios desproporcionados en relación a las rentas, determinados en base a factores como el sexo y la edad, ambos inherentes a la condición 
bumana, afectan el libre e igualitario acceso a las acciones de salud que el Estado está obligado a garantizar. Para ajustarse a la garantía constitucional reseñada, el legislador debió establecer parámetros prudentes, dentro de latitudes razonables, al determinar las condiciones a las que debe ajustarse la fijación del precio de un seguro de salud que se contrate con una Isapre.

Por otra parte, dicho mecanismo potencia una discriminación en contra de las mujeres, los adultos mayores y los niños menores de dos años, que no tiene justificación racional y, por lo tanto, no se aviene a la Constitución;

CENTÉSIMO QUINCUAGÉSIMO SEXTO: Que en el inciso cuarto del numeral 9o de su artículo 19, la Constitución faculta a la ley para establecer 'cotizaciones obligatorias', las que son administradas por 'instituciones públicas o privadas'. Se les asegura, por tanto, a las Isapres, un ingreso constante. Frente a esa regla el legislador se encuentra obligado a ponderar la obligación del trabajador (afiliado-cotizante) de pagar tales cotizaciones obligatorias y, al mismo tiempo, propender al cumplimiento del deber de asegurar la 'protección de la salud', previsto en el inciso primero de la misma disposición constitucional. No obstante, el mecanismo de reajustabilidad definido por el legislador en esta materia genera un desequilibrio entre el cobro de las cotizaciones y la protección del derecho a la salud, que deja a este último sin la tutela que la Constitución exige;

CENTÉSIMO QUINCUAGÉSIMO SÉPTIMO: Que, en sintesis, los numerales 1, 2, 3 y 4 del inciso tercero del artículo 38 ter de la Ley $N^{\circ} 18.933$ resultan contrarios a la Constitución, en cuanto impiden garantizar el libre e igualitario acceso de las personas a las acciones de promoción, protección y recuperación de la salud y el derecho que les asiste a elegir el sistema de salud al que deseen acogerse, sea éste estatal o privado, ambas garantías previstas en el número $9^{\circ}$ del artículo 19 de la Constitución Política de la República. Además, el aumento desmedido del precio de los planes de salud al que conduce la amplitud no razonable que la disposición en examen permite, especialmente en los tramos de edad superiores, produce la calidad de 'cotizante cautivo' que obliga a emigrar a un sistema al que la persona no desea pertenecer, lo que riñe directamente con el texto constitucional;".

\section{El Tribunal DeTermina la inCONSTITUCiONALIDAD DEL $\mathrm{N}^{\circ} 4$ DEL INCISO} $3^{\circ}$ Del artículo 38 Ter, en la medida Que entrega a la Superintendencia DE SALUd Un MARGEN DE DISCRECIONALIDAD QUE LA NORMa CONSTITUCIONAL NO PERMITE, YA QUE LA LEY DEBE REGULAR LA FORMA Y CONDICIONES EN QUE SE EJERCEN LAS ACCIONES DE SALUD CON UN GRADO DE PRECISIÓN TAL QUE IMPIDA UNA DISCRECIONALIDAD ADMINISTRATIVA QUE VULNERE LOS DERECHOS FUNDAMENTALES A LA PROTECCIÓN DE LA SALUD Y A LA SEGURIDAD SOCIAL

“CENTÉSIMO QUINCUAGÉSIMO OCTAVO: Que en relación al número 4 citado, debe agregarse que respecto de la sola formulación del precepto impugnado, sin vinculación con el artículo segundo transitorio de la Ley $N^{\circ} 20.015$, esto es, en su validez como norma 
permanente habiendo transcurrido el primer periodo de diez años que este último contempla, cabe la interrogante sobre su conformidad con la exigencia constitucional dispuesta en el inciso cuarto del numeral $9^{\circ}$ del artículo 19 citado. Esto es, como esta Magistratura ya lo ha expuesto, apreciar si el grado de discrecionalidad que el precepto bajo control le entrega a la Superintendencia de Salud para actuar en la materia referida, corresponde a la envergadura de los bienes jurídicos que su ejercicio abarca o cubre. En efecto, la forma y condiciones como se prestan las acciones de salud, que es la materia cobijada en la reserva legal que nos ocupa, se refiere a un deber del Estado que está destinado a posibilitar que se cumpla la garantía del derecho a la protección de la salud de las personas. Por lo tanto, sin pretender que el legislador determine en este caso un tipo de actividad administrativa plenamente reglada, como se denomina en doctrina, las referidas forma y condiciones de la ejecución de las acciones de salud si deben determinarse por la ley con un grado de precisión tal que impida que el ejercicio de la discrecionalidad administrativa se extienda a la vulneración de los derechos constitucionales;".

\section{El Tribunal determina QUe las Disposiciones legales CUeSTIONADAS}

VULNERAN EL DERECHO A LA SEGURIDAD SOCIAL EN CONEXIÓN CON EL DERECHO

A LA SALUD EN LA MEDIDA QUE LOS FACTORES DE CADA TABLA QUE SURGE DEL $\mathrm{N}^{\circ} 4$ DEL INCISO $3^{\circ}$ DEL ARTÍCULO 38 TER, NO ESTABLECE PRECISIONES NI REGLAS ESPECIALES PARA LAS PERSONAS QUE SE ENCUENTRAN EN LA CONTINGENCIA DE OBTENER LAS PRESTACIONES DE SEGURIDAD SOCIAL PARA PROTEGER SU DERECHO A LA

\section{VIDA Y A UN NIVEL DE VIDA DIGNO}

De esta manera, el aumento exponencial de precios de los planes de salud dejan a las personas, en su vejez, cuando más necesitan del apoyo de las prestaciones, en la imposibilidad de pagarlas por su alto monto y dejándolas en la indignidad, incumpliéndose el deber del Estado de garantizarles a tales personas el acceso al goce de prestaciones básicas uniformes, en omisión de todo sentido de solidaridad y equidad social común a todos los derechos sociales.

“CENTÉSIMO QUINCUAGÉSIMO NOVENO: Que, en tercer lugar, en relación al derecho a la seguridad social garantizado en el artículo 19, $N^{\circ} 18^{\circ}$, de la Constitución, en intima relación con el derecho a la protección de la salud ya analizado, es necesario resaltar que también resulta infringido por los preceptos legales en análisis. Lo anterior ocurre, toda vez que, no estableciéndose en la fijación de la relación máxima entre el más alto y el más bajo de los factores de cada tabla que surge del número 4 del inciso tercero del artículo 38 ter, ninguna precisión ni regla especial para las personas que se encuentran en situación de obtener las prestaciones de seguridad social, se vulnera su propósito esencial: 'La Seguridad Social tiene su razón de ser en que los administrados están sujetos a contingencias sociales. La necesidad de proteger de estas contingencias al ser humano y a los que de él dependen emana de su derecho a la existencia; de la obligación de conservar 
su vida y hacerlo en un nivel digno y acorde con su condición de tal' (Héctor Humeres Noguer: Derecho del Trabajo y de la Seguridad Social, Tomo III, ob. cit., p.23);

CENTÉSIMO SEXAGÉSIMO: Que, en efecto, el aumento de los precios al amparo de la norma cuestionada puede traer consigo, y asi ocurre en la realidad de muchas personas, una completa imposibilidad de costearlos, ocasionando la indignidad que ello significa para el transcurrir de sus vidas y la evidencia de la falta de concreción de la obligación que el texto de la Constitución le asigna al Estado para dirigir su acción a garantizar el acceso de todos los habitantes al goce de prestaciones básicas uniformes;

CENTÉSIMO SEXAGÉSIMO PRIMERO: Que de la vigencia de los números 1, 2, 3 y 4 del inciso tercero del artículo 38 ter citado, se desprende una situación contraria a los principios de solidaridady de equidad que informan no sólo la seguridad social, sino todo el conjunto de derechos fundamentales sociales garantizados en nuestra Constitución, lo que exige de esta Magistratura declararlos como contrarios a ella;".

\section{EFECTOS DE LA SENTENCIA DE INCONSTITUCIONALIDAD}

20.1. El Tribunal Constitucional en su sentencia obliga al legislador a determinar las tablas de factores y la fijación de los factores de cada una de ellas dentro de parámetros razonables y proporcionados, sin establecer criterios de discriminación por el solo transcurso de la edad o por sexo, expulsando del ordenamiento jurídico los numerales 2, 4 ó 7 del artículo 93, con efectos ex nunc, vale decir, desde la publicación de la sentencia, sin afectar situaciones anteriores a la fecha del fallo ya consolidadas en el ordenamiento jurídico.

"CENTÉSIMO SEXAGÉSIMO TERCERO: Que este Tribunal ha sentenciado estrictamente bajo los presupuestos exigidos por el artículo 93, inciso primero, $N^{\circ} 7^{\circ}$, de la Constitución, no emitiendo, en consecuencia, pronunciamiento alguno respecto de las demás normas contenidas en el artículo 38 ter de la Ley $N^{\circ}$ 18.933, actual artículo 199 del D.F.L. No 1, de 2005, del Ministerio de Salud. Esta Magistratura estima necesario, además, hacer presente que la determinación de la estructura de las tablas de factores y la fijación de los factores de cada una de ellas deberán ajustarse a lo que establezcan, en uso de sus facultades, los órganos colegisladores para dar cabal cumplimiento a lo resuelto en este fallo;

CENTÉSIMO SEXAGÉSIMO CUARTO: Que, asimismo, lo resuelto en esta sentencia no prejuzga, en sentido alguno, lo que pueda resolverse sobre la constitucionalidad de tales normas en procedimientos futuros o respecto de las acciones de inaplicabilidad por inconstitucionalidad cuya resolución se encuentra pendiente ante esta Magistratura. Lo anterior se apega al numeral segundo de artículo $47 \mathrm{~F}$ de la Ley $N^{\circ}$ 17.997, según el cual unicamente procede declarar la inadmisibilidad de acciones de inaplicabilidad por inconstitucionalidad en razón de un pronunciamiento previo del Tribunal Constitucional, concurriendo tres requisitos copulativos: a) que la cuestión se promueva respecto 
de un precepto legal que haya sido declarado expresamente conforme a la Constitución, b) que el pronunciamiento previo en cuestión haya sido emitido en un control preventivo o conociendo de un requerimiento, y c) que se invoque el mismo vicio que fue materia de la respectiva sentencia previa;

CENTÉSIMO SEXAGÉSIMO QUINTO: Que ninguno de los señalados presupuestos podría configurarse respecto de las demás normas contenidas en el artículo 38 ter de la Ley $N^{o} 18.933$ o del D.F.L. No 1, de 2005, del Ministerio de Salud, respecto de las cuales el Tribunal no ha declarado la inconstitucionalidad, pues no se emite pronunciamiento sobre ellas y la presente sentencia no se dicta en el contexto de un control preventivo ni con ocasión de un requerimiento, ya que este Tribunal actuó de oficio en la presente cuestión. Además, cabe hacer presente que la referida norma del numeral segundo del artículo 47 $F$ de la Ley $N^{o}$ 17.997, debe ser interpretada en el sentido de no impedir el acceso al Tribunal Constitucional de quienes pudieran, en el futuro, solicitar su intervención;

CENTÉSIMO SEXAGÉSIMO SEXTO: Que el artículo 94 de la Constitución establece al respecto que: 'No obstante, el precepto declarado inconstitucional en conformidad a lo dispuesto en los numerales 2, 4 ó 7 del artículo 93, se entenderá derogado desde la publicación en el Diario Oficial de la sentencia que acoja el reclamo, la que no producirá efecto retroactivo;

CENTÉSIMO SEXAGÉSIMO SÉPTIMO: Que la doctrina y esta misma sentencia han señalado que esta norma consagra expresamente que las sentencias del Tribunal Constitucional producen efectos ex nunc (Nogueira, Humberto, 'El control represivo y abstracto de inconstitucionalidad de leyes en la reforma constitucional de 2005 de las competencias del Tribunal Constitucional y los efectos de sus sentencias', en: Francisco Zúñiga (coordinador), Reforma constitucional, Editorial LexisNexis, 2005, p. 615), esto es, produce efectos desde la publicación del fallo 'hacia el futuro, no afectando situaciones anteriores producidas al amparo de dicha norma' (ob. cit., p. 608). De esta manera, 'ni el Tribunal Constitucional ni el legislador orgánico constitucional podrán dar efecto retroactivo a las sentencias que expulsen de nuestro ordenamiento jurídico disposiciones de rango constitucional' (ob. cit., p. 615).

Este Tribunal Constitucional, por su parte, ha señalado que 'el hecho de que su sentencia carezca de efectos retroactivos significa que no afecta situaciones acaecidas ni actos realizados con anterioridad a su publicación en el Diario Oficial' (Sentencia Rol 597, considerando 50);

CENTÉSIMO SEXAGÉSIMO OCTAVO: Que como consecuencia de lo anterior se puede concluir que la irretroactividad se traduce en que la sentencia no puede afectar 'situaciones anteriores producidas al amparo de dicha norma' (Nogueira, Humberto, 'El control represivo y abstracto de inconstitucionalidad de leyes en la reforma constitucional de 2005 de las competencias del Tribunal Constitucional y los efectos de sus sentencias', ob. cit., p. 467), ni 'situaciones acaecidas ni actos realizados con anterioridad'(Sentencia Rol 597). Asi, la sentencia que dicte el Tribunal Constitucional no puede afectar situaciones 
consolidadas, esto es, nacidas y concluidas bajo el imperio de la o las normas declaradas inconstitucionales;

CENTÉSIMO SEXAGÉSIMO NOVENO: Que la regla constitucional señalada resulta de una adecuada consideración entre la seguridad jurídica y la supremacía constitucional. Si bien la supremacía constitucional exigiría la expulsión de todas las normas que pugnen con la Constitución, la seguridad jurídica exige limitar dichos efectos para no afectar a quienes actuaron bajo la expectativa de que el marco legal vigente era regular;".

20.2. El Tribunal Constitucional junto con determinar que el contrato de salud entre una ISAPRE y el cotizante beneficiario tiene elementos de orden público, por el hecho de regular el ejercicio de derechos fundamentales como el derecho a la protección de la salud en armonía con el derecho a la seguridad social, afirma su característica de ser un contrato indefinido de tracto sucesivo, el cual se revisa periódicamente, por lo cual el cambio de marco jurídico dentro del cual se desarrolla el contrato, por expulsión de algunas de sus normas del ordenamiento jurídico, exige hacia el futuro el cambio de las normas contractuales:

"CENTÉSIMO SEPTUAGÉSIMO: Que, sin embargo, hay que considerar la naturaleza del contrato de salud que junto con ser un contrato con elementos de orden público, lo es de tracto sucesivo, no de ejecución instantánea. A diferencia de, por ejemplo, un contrato de compraventa, el contrato de salud origina una relación de permanencia entre la Isapre y el cotizante. De hecho, esta es la razón por la cual se permiten revisiones en las condiciones del contrato. Las circunstancias fácticas que se tuvieron en consideración al momento de celebrar el contrato pueden cambiar y por ello se admiten ciertas modificaciones (en un marco de razonabilidad y proporcionalidad). Lo mismo autoriza a que, si cambia el marco jurídico aplicable nada menos que por una declaración de inconstitucionalidad, entonces cambien también - hacia futuro- las cláusulas del contrato;

CENTÉSIMO SEPTUAGÉSIMO PRIMERO: Que, además, debe tenerse presente que la derogación o expulsión de una norma por una declaración de inconstitucionalidad tiene un alcance distinto a una derogación de una norma por el legislador. El Tribunal Constitucional es un órgano que falla de acuerdo a derecho (artículo 92 de la Carta Fundamental); no es un ente de deliberación politica que se pronuncie sobre cuestiones de mérito, como los órganos colegisladores. Por ello, su declaración de inconstitucionalidad se basa en que la norma posee un vicio. En cambio, la derogación realizada por el legislador se basa en una nueva evaluación politica de la situación. Es una decisión de mérito politico. De hecho, es posible hacer un paralelo entre la derogación por inconstitucionalidad efectuada por el Tribunal Constitucional y la derogación efectuada por el legislador, con la invalidación y la revocación de un acto administrativo que efectúa la Administración. Unas situaciones se basan en un vicio y las otras, en cambio, en una valoración de mérito;

CENTÉSIMO SEPTUAGÉSIMO OCTAVO: Que en el presente caso existe una identidad entre las normas constitucionales que se consideran infringidas con aquellas identificadas 
en las sentencias de inaplicabilidad previas. Se han declarado vulnerados los numerales $2^{\circ}, 9^{\circ}$ y $18^{\circ}$ del artículo 19 de la Constitución. Por tanto, los vicios que en esta sentencia se invocan son los mismos que se consideraron en las inaplicabilidades previas;". 